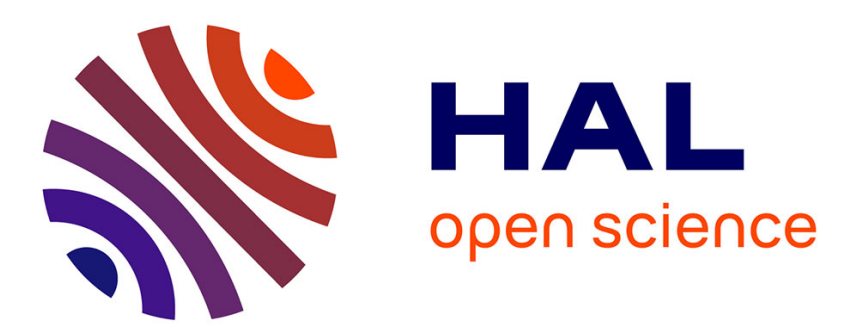

\title{
A bifunctional sea anemone peptide with Kunitz type protease and potassium channel inhibiting properties.
}

Steve Peigneur, Bert Billen, Rita Derua, Etienne Waelkens, Sarah Debaveye, László Béress, Jan Tytgat

\section{- To cite this version:}

Steve Peigneur, Bert Billen, Rita Derua, Etienne Waelkens, Sarah Debaveye, et al.. A bifunctional sea anemone peptide with Kunitz type protease and potassium channel inhibiting properties.. Biochemical Pharmacology, 2011, 82 (1), pp.81. 10.1016/j.bcp.2011.03.023 . hal-00701259

\section{HAL Id: hal-00701259 \\ https://hal.science/hal-00701259}

Submitted on 25 May 2012

HAL is a multi-disciplinary open access archive for the deposit and dissemination of scientific research documents, whether they are published or not. The documents may come from teaching and research institutions in France or abroad, or from public or private research centers.
L'archive ouverte pluridisciplinaire HAL, est destinée au dépôt et à la diffusion de documents scientifiques de niveau recherche, publiés ou non, émanant des établissements d'enseignement et de recherche français ou étrangers, des laboratoires publics ou privés. 


\section{Accepted Manuscript}

Title: A bifunctional sea anemone peptide with Kunitz type protease and potassium channel inhibiting properties.

Authors: Steve Peigneur, Bert Billen, Rita Derua, Etienne Waelkens, Sarah Debaveye, László Béress, Jan Tytgat

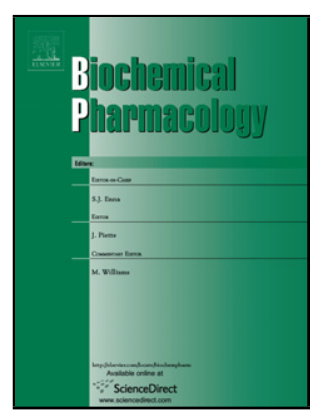

PII:

S0006-2952(11)00210-3

DOI: doi:10.1016/j.bcp.2011.03.023

Reference: BCP 10863

To appear in: $\quad B C P$

Received date: $\quad 10-2-2011$

Revised date: 24-3-2011

Accepted date: $\quad$ 25-3-2011

Please cite this article as: Peigneur S, Billen B, Derua R, Waelkens E, Debaveye S, Béress L, Tytgat J, A bifunctional sea anemone peptide with Kunitz type protease and potassium channel inhibiting properties., Biochemical Pharmacology (2008), doi:10.1016/j.bcp.2011.03.023

This is a PDF file of an unedited manuscript that has been accepted for publication. As a service to our customers we are providing this early version of the manuscript. The manuscript will undergo copyediting, typesetting, and review of the resulting proof before it is published in its final form. Please note that during the production process errors may be discovered which could affect the content, and all legal disclaimers that apply to the journal pertain. 


\title{
A BIFUNCTIONAL SEA ANEMONE PEPTIDE WITH KUNITZ TYPE PROTEASE AND POTASSIUM CHANNEL INHIBITING PROPERTIES.
}

\author{
Steve Peigneur ${ }^{1}$, Bert Billen ${ }^{1}$, Rita Derua ${ }^{2}$, Etienne Waelkens ${ }^{2}$, Sarah Debaveye ${ }^{1}$, \\ László Béress ${ }^{3}$, Jan Tytgat ${ }^{1 \$}$
}

From the ${ }^{1}$ Laboratory of Toxicology, University of Leuven (K.U. Leuven), Campus Gasthuisberg O\&N2, Herestraat 49, P.O. Box 922, B-3000 Leuven, Belgium, ${ }^{2}$ Laboratory of Protein Phosphorylation and Proteomics, University of leuven, ${ }^{3}$ Clinic for Immunology and Pheumatology, Research group Experimental Peptide chemistry, medical High School Hanover, Germany

$\S$ To whom correspondence should be addressed. Tel.: +32 163234 03; Fax: +32 163234 05; E-mail: jan.tytgat@pharm.kuleuven.be

Abstract Sea anemone venom is a known source of interesting bioactive compounds, including peptide toxins which are invaluable tools for studying structure and function of voltage-gated potassium channels. APEKTx1 is a novel peptide isolated from the sea anemone Anthopleura elegantissima, containing 63 amino acids cross-linked by 3 disulfide bridges. Sequence alignment reveals that APEKTx1 is a new member of the type 2 sea anemone peptides targeting voltage-gated potassium channels $\left(K_{\mathrm{v}}\right.$ 's), which also include the kalicludines from Anemonia sulcata. Similar to the kalicludines, APEKTx1 shares structural homology with both the basic pancreatic trypsin inhibitor (BPTI), a very potent Kunitz-type protease inhibitor, and dendrotoxins which are powerful blockers of voltage-gated potassium channels. In this study, APEKTx1 has been subjected to a screening on a wide range of 23 ion channels expressed in Xenopus leavis oocytes: 13 cloned voltage-gated potassium channels $\left(K_{v} 1.1-K_{v} 1.6, K_{v} 1.1\right.$ triple mutant, $K_{v} 2.1, K_{v} 3.1, K_{v} 4.2, K_{v} 4.3$, hERG, the insect channel Shaker IR), 2 cloned hyperpolarization-activated cyclic nucleotidesensitive cation non-selective channels (HCN1 and HCN2) and 8 cloned voltage-gated sodium channels ( $\mathrm{Na}_{\mathrm{v}} 1.2-\mathrm{Na}_{\mathrm{v}} 1.8$ and the insect channel DmNa 1$)$. Our data shows that APEKTx1 selectively blocks $K_{V} 1.1$ channels in a very potent manner with an $I_{50}$ value of $0.9 \mathrm{nM}$. Furthermore, we compared the trypsin inhibitory activity of this toxin with BPTI. APEKTx1 inhibits trypsin with a dissociation constant of $124 \mathrm{nM}$. In conclusion, this study demonstrates that APEKTx1 has the unique feature to combine the dual functionality of a potent and selective blocker of $K_{V} 1.1$ channels with that of a competitive inhibitor of trypsin.

Keywords Anthopleura elegantissima $\cdot \mathrm{K}_{\mathrm{V}}$ channel inhibitor $\cdot$ sea anemone toxin · protease inhibitor .

\section{Introduction}

Among ion channels, potassium channels are the most diverse class of ion channels and they are key determinants of neuronal excitability. They regulate a variety of cellular processes and functions such as heart rate, neurotransmitter release and nerve conduction, insulin secretion, blood pressure and muscle contraction [1,2]. In the mammalian genome more than 100 genes are encoding the pore forming $\alpha$ subunits and auxiliary $\beta$ subunits of $\mathrm{K}^{+}$channels. Together with these numerous genes, the presence of spliced variants, association with chaperone and scaffolding molecules and the formation of heteromultimeric channels contribute greatly to the diversity of the $\mathrm{K}^{+}$channel family [2]. This family has been divided into 15 subfamilies of which the voltage gated potassium channels $\left(\mathrm{K}_{\mathrm{V}}\right)$ represent one of these subfamilies [3]. They determine neuronal intrinsic electrical excitability by repolarization of the membrane after initiation of the action potential [4]. Upon depolarization of the membrane, $\mathrm{K}_{\mathrm{V}}$ channels will open within $1 \mathrm{~ms}$, allowing the flux of $\mathrm{K}^{+}$ions driven by their electrochemical gradient [1,2]. Functional $\mathrm{K}_{\mathrm{V}}$ channels are formed by a complex of four pore forming $\alpha$ subunits associated with one or 
more auxiliary $\beta$ subunits. Each $\alpha$ subunit consists of six transmembrane spanning segments (S1-S6). The first four transmembrane segments form the voltage sensing domain with S4 serving as the voltage sensor. This $\mathrm{S} 4$ segment has been modeled using the crystal structure of the bacterial $\mathrm{K}_{\mathrm{V}}$ channel $\mathrm{K}_{\mathrm{V}} \mathrm{AP}$ and contains 4 conserved Arg residues. These positively charged basic residues display a net movement outwards upon depolarization allowing conformational changes resulting in the opening of the pore $[5,6]$. The pore region of the channels is formed by the S5 and S6 segments which are connected by a re-entrant P-loop. The P-loop contains an extremely well conserved domain among the $\mathrm{K}_{\mathrm{V}}$ channels, the so-called signature sequence (-TXGYGD-) and comprises the selectivity filter, the pore helix and the turret region [7]. The auxiliary $\beta$ subunits of $K_{V}$ channels $\left(K_{V} \beta\right)$ are cytoplasmic proteins, capable of modifying $K_{V}$ channel biophysical properties.

Since the beginning of last century sea anemones have been studied with an increasing interest. Although a number of sea anemone toxins have been isolated and characterized, these animals remain poorly studied in comparison with other venomous animals such as scorpions, spiders, cone snails or snakes. Sea anemones are a known pharmacological treasure of biological active compounds acting upon a diverse panel of ion channels such as TRPV1, voltage-gated sodium and potassium channels [8-11]. Of these different toxins those that target sodium channels are the best studied group with more then 100 known toxins [12]. In contrast, no more then 12 potassium channel toxins have been characterized to date. Based on structural differences and activity profile, these potassium channel toxins can be divided into 4 structural classes [11,13-15]. Up to date 6 toxins from A. elegantissima have been isolated and characterized: APE1-1, APE1-2, APE2-2 and ApC which are type 1 sodium channel toxins; APETx1 a selective modifier of the human ether a go-go related gene $\mathrm{K}^{+}$channel (hERG) and APETx2 which specifically inhibits the Acid Sensing Ion Channel (ASIC3) [15-18]. In this work we present the purification, biochemical analysis and electrophysiological characterization of a very potent and selective $\mathrm{K}_{\mathrm{V}} 1.1$ blocker which represents the newest member of the sea anemone type 2 potassium channel toxins.

\section{Material and methods}

\subsection{Toxin purification.}

The toxin APEKTx1 was purified as described previously $[16,17,19]$. The fraction containing APEKTx1 was further purificated by RP-HPLC with a semi preparative Vydac C18 column (4.6X250 mm). Solvent A was $0.1 \%$ TFA in water, solvent B was $0.085 \%$ TFA in acetonitrile. A linear gradient from 0 to $80 \%$ solution B was developed for $80 \mathrm{~min}$ at a flow rate of $1 \mathrm{ml} / \mathrm{min}$. A second purification was performed in the same conditions as described above. All final fractions were dried by speed-vac evaporation and stored at $-20^{\circ} \mathrm{C}$.

\subsection{Biochemical characterization of toxins.}

The mass of the intact toxin was measured by MALDI-TOF (4800 Analyzer, Applied Biosystems, USA) as well as by ESI-QUAD analysis (4000QTRAP, Applied Biosystems, USA).

The toxin peptide was subjected to Edman degradation on an Applied Biosystems Procise instrument. The toxin was digested with legumain (R\&D Systems, USA). A MALDI TOF/TOF instrument (4800 Analyzer, Applied Biosystems, USA) was used for de novo sequencing analysis of the obtained fragments. These fragments were subjected to MS/MS analysis and the spectra were manually interpreted.

\subsection{Expression of voltage-gated ion channels in Xenopus laevis oocytes.}

For the expression of the VGPCs ( $\mathrm{rK}_{\mathrm{V}} 1.1$ (Accesion number: NM173095), $\mathrm{rK}_{\mathrm{V}} 1.2(\mathrm{NM} 012970), \mathrm{hK}_{\mathrm{V}} 1.3$ (L23499), rK ${ }_{\mathrm{V}} 1.4$ (NM012971), $\mathrm{rK}_{\mathrm{V}} 1.5$ (NM012972), rK $\mathrm{V}_{\mathrm{V}} 1.6$ (NM575671), Shaker IR (CG12348), $\mathrm{rK}_{\mathrm{V}} 2.1$ (NM013186), $\mathrm{hK}_{\mathrm{V}} 3.1 \quad(\mathrm{NM} 004976), \mathrm{rK}_{\mathrm{V}} 4.2 \quad(\mathrm{NM} 031730), \quad \mathrm{rK}_{\mathrm{v}} 4.3$ (NM031739), hERG (NM000238), mHCN 1 (NM010408), mHCN 2 (NM008226) and the VGSCs ( $\mathrm{rNa}_{v} 1.2$ (NM012647), 
$\mathrm{rNa}_{\mathrm{V}} 1.3$ (NM012647), $\mathrm{rNa}_{\mathrm{V}} 1.4$ (M26643), $\mathrm{hNa}_{\mathrm{V}} 1.5$ (NM198056), $\mathrm{mNa}_{\mathrm{V}} 1.6$ (L39018), $\mathrm{rNa}_{\mathrm{V}} 1.7$ (AF000368), rNa 1.8 (NM017247), $\mathrm{r} \beta 1$ (NM017288), h $\beta 1$ (NM001037) and the insect channel DmNa 1 (NC004354)) in Xenopus oocytes, the linearized plasmids were transcribed using the T7 or SP6 mMESSAGE-mMACHINE transcription kit (Ambion, USA). The harvesting of stage V-VI oocytes from anaesthetized female Xenopus laevis frog was previously described [20]. Oocytes were injected with $50 \mathrm{nl}$ of cRNA at a concentration of $1 \mathrm{ng} / \mathrm{nl}$ using a micro-injector (Drummond Scientific, USA). The oocytes were incubated in a solution containing (in $\mathrm{mM}$ ): $\mathrm{NaCl}, 96 ; \mathrm{KCl}, 2 ; \mathrm{CaCl}_{2}, 1.8 ; \mathrm{MgCl}_{2}, 2$ and $\mathrm{HEPES}, 5$ ( $\mathrm{pH}$ 7.4), supplemented with $50 \mathrm{mg} / \mathrm{l}$ gentamycin sulfate.

\subsection{Electrophysiological recordings.}

Two-electrode voltage-clamp recordings were performed at room temperature $\left(18-22^{\circ} \mathrm{C}\right)$ using a Geneclamp 500 amplifier (Molecular Devices, USA) controlled by a pClamp data acquisition system (Axon Instruments, USA). Whole cell currents from oocytes were recorded 1-4 days after injection. Bath solution composition was ND96 (in $\mathrm{mM}$ ): $\mathrm{NaCl}, 96 ; \mathrm{KCl}, 2 ; \mathrm{CaCl}_{2}, 1.8 ; \mathrm{MgCl}_{2}, 2$ and HEPES, 5 (pH 7.4) or $\mathrm{HK}$ (in $\mathrm{mM}$ ): $\mathrm{NaCl}, 2 ; \mathrm{KCl}, 96 ; \mathrm{CaCl}_{2}, 1.8 ; \mathrm{MgCl}_{2}, 2$ and HEPES, 5 (pH 7.4). Voltage and current electrodes were filled with $3 \mathrm{M} \mathrm{KCl}$. Resistances of both electrodes were kept between 0.5-1.5 M $\Omega$. The elicited currents were filtered at $1 \mathrm{kHz}$ and sampled at $0.5 \mathrm{kHz}$ (for potassium currents) or at $20 \mathrm{kHz}$ (for sodium currents) using a four-pole low-pass Bessel filter. Leak subtraction was performed using a -P/4 protocol. $\mathrm{K}_{\mathrm{V}} 1.1-\mathrm{K}_{\mathrm{V}} 1.6$ and Shaker currents were evoked by $500 \mathrm{~ms}$ depolarizations to $0 \mathrm{mV}$ followed by a $500 \mathrm{~ms}$ pulse to $-50 \mathrm{mV}$, from a holding potential of $-90 \mathrm{mV}$. Current traces of hERG channels were elicited by applying a $+40 \mathrm{mV}$ prepulse for $2 \mathrm{~s}$ followed by a step to $-120 \mathrm{mV}$ for $2 \mathrm{~s} . \mathrm{K}_{\mathrm{V}} 2.1, \mathrm{~K}_{\mathrm{V}} 3.1$ and $\mathrm{K}_{\mathrm{V}} 4.2, \mathrm{~K}_{\mathrm{V}} 4.3$ currents were elicited by $500 \mathrm{~ms}$ pulses to $+20 \mathrm{mV}$ from a holding potential of $-90 \mathrm{mV}$. Sodium current traces were, from a holding potential of $-90 \mathrm{mV}$, evoked by $100 \mathrm{~ms}$ depolariarions to $\mathrm{V}_{\max }$ (the voltage corresponding to maximal sodium current in control conditions). In order to investigate the current-voltage relationship, current traces were evoked by $10 \mathrm{mV}$ depolarization steps from a holding potential of $-90 \mathrm{mV}$. $\mathrm{gV}$ curves were calculated from IV relationships as follows: $g_{K}=I_{K} /\left(E_{m}-E_{K}\right)$ with $E_{\mathrm{k}}=(\mathrm{RT} / z \mathrm{~F}) \ln [\mathrm{K} \# 0]_{\mathrm{o}} /[\mathrm{K} \# 0]_{\mathrm{i}}$. In these equations $\mathrm{g}_{\mathrm{K}}$ represents the conductance, $I_{K}$ the potassium current, $E_{m}$ the membrane potential, $E_{K}$ the reversal potential, R the gas constant $(8.31 \mathrm{~J} / \mathrm{K} . \mathrm{mol}), \mathrm{T}$ the temperature, $z$ the charge of the ion (for $\mathrm{K}^{+}$ions: $\mathrm{z}=1$ ), F the Faraday's constant $(96.500 \mathrm{C} / \mathrm{mol})$, [K \#0]。 and $[\mathrm{K} \# 0]_{\mathrm{I}}$ respectively are the extracellular and intracellular $\mathrm{K}^{+}$ion concentrations. The values of $\mathrm{I}_{\mathrm{K}}$ or $\mathrm{g}_{\mathrm{K}}$ were plotted as function of voltage and fitted using the Boltzmann equation: $g_{K} / g_{\max }=[1+(\exp (V g-$ $V) / k]^{-1}$, were gmax represents maximal $\mathrm{gK}, \mathrm{Vg}$ is the voltage corresponding to half-maximal conductance, and $\mathrm{k}$ is the slope factor. To assess the concentration dependency of the APEKTx 1 induced inhibitory effects, a concentration-response curve was constructed, in which the percentage of current inhibition was plotted as a function of toxin concentration. Data were fitted with the Hill equation: $y=100 /[1$ $\left.+\left(\mathrm{IC}_{50} /[\text { toxin }]\right)^{h}\right]$, were $y$ is the amplitude of the toxin-induced effect, $\mathrm{IC}_{50}$ is the toxin concentration at half-maximal efficacy, [toxin] is the toxin concentration, and $h$ is the Hill coefficient. To investigate the bimolecular kinetics of toxin inhibition, oocytes expressing wild type $\mathrm{K}_{\mathrm{V}} 1.1$ channels were depolarized to o $\mathrm{mV}$ for $0.5 \mathrm{~s}$ from a holding potential of $-90 \mathrm{mV}$ every $5 \mathrm{~s}$, both in the absence and presence of different concentrations of toxin. The obtained current values were plotted as a function of time. Data were fitted with the following exponential equation: $\mathrm{y}=A e^{-t / \tau}$, where $\mathrm{t}$ represents the time, $\mathrm{A}$ is the amplitude of the current and $\tau$ is the time constant for toxin binding $\left(\tau_{\text {on }}\right)$ or toxin unbinding $\left(\tau_{\text {off }}\right)$. The first-order association rate constant $\left(k_{o n}\right)$ was calculated using following equation: $\tau_{o n}=\left(k_{o n}+k_{o f f}\right)^{-1}$. The first-order dissociation constant $\left(k_{o f f}\right)$ was calculated using the equation: $\tau_{o f f}=k_{o f f}{ }^{-1}$. Comparison of two sample means was made using a paired Student's t test $(\mathrm{p}<0.05)$. All data represent at least 3 independent experiments $(\mathrm{n} \geq 3)$ and are presented as mean \pm standard error.

\subsection{Kunitz-type inhibition activity.}


The possible trypsin inhibition activity of APEKTx1 was measured spectrophotometrically as described previosly [21]. Briefly, aliquots containing a final concentration of $3 \mu \mathrm{M}$ trypsin (from bovine pancreas, TPCK treated, Sigma-Aldrich, USA) were incubated with various concentrations of peptides in $5 \mathrm{mM}$ $\mathrm{CaCl}_{2}$ and $50 \mathrm{nM}$ Tris- $\mathrm{HCl}, \mathrm{pH}$ 7.8. After incubation for $3 \mathrm{~h}$ at $25^{\circ} \mathrm{C}$ the remaining trypsin activity was determined by addition of $5 \mu \mathrm{l}$ of a $5 \mathrm{mM} \mathrm{N} \alpha$-benzoyl-DL-arginine p-nitroanilide (BAPNA, SigmaAldrich,USA). Paranitroanaline release was measured at $405 \mathrm{~nm}$.

\subsection{Molecular modeling.}

APEKTx1 was modeled using the publicly available program MODELLER9v8 (http://www.salilab.org/modeller) using textilinin-1, a Kunitz-type serine protease inhibitor from the venom of the Australian common brown snake Pseudonaja textilis (PDB code 3BYB; http://www.pdb.org/pdb) as template.

\section{Results}

\subsection{Purification of APEKTx1.}

The screening of fractions obtained from the sea anemone A. elegantissima, after anion and cation exchange and gel filtration, yielded one fraction which was able to fully block $\mathrm{K}_{\mathrm{V}} 1.1$ channels. This fraction was further purified in 2 steps using reversed-phase HPLC. A linear gradient from 0 to $80 \%$ solution B was developed for $80 \mathrm{~min}$ at a flow rate of $1 \mathrm{ml} / \mathrm{min}$. A second purification was performed in the same conditions as described above (fig.1).

\subsection{Biochemical properties.}

With MALDI analysis in the linear mode, a broad mass peak with an apex mass of 7468.8 Da was measured. This experimental mass of $7475 \mathrm{Da}$ corresponds well with the theoretical mass of $7468.5 \mathrm{Da}$. During ESI analysis, a mass of $7484.8 \mathrm{Da}$ was observed, suggesting an oxidation of Met32. The intact toxin was subjected to Edman degradation. Since only the 20 first N-terminal amino acids could be reliably sequenced, we subjected the toxin to a proteolytic treatment in order to obtain fragments amenable to de novo sequencing analysis by MALDI TOF/TOF instrument. Digestion of the toxin by trypsin, gluC, thermolysin turned out to be unsuccessful. Finally, an asparaginylendopeptidase was found to cut the toxin peptide into smaller fragments. The digestion was executed according to the protocol of the manufacturer. After digestion, the resulting peptides were separated and desalted by HPLC. The HPLC fractions were dried by speed-vac evaporation and resolubilized in alfa-cyano 4-hydrocinnamic acid matrix solution before analysis by MALDI TOF/TOF. The protein sequence data reported in this paper will appear in the UniProt Knowledgebase under the accession number P86862.

\subsection{Electrophysiological experiments.}

Sequence alignment (fig. 2A) indicated that APEKTx1 is a new member of the type 2 sea anemone peptides directing against voltage-gated potassium channels, which also include the kalicludines from $A$. sulcata and SHTX II from Stichodactyla haddoni [21,22]. From figure 2B it can be seen that APEKTx1 also shares homology with protease inhibitors from other sea anemones and with the potent Kunitz-type protease inhibitor Bovine Pancreatic Trypsin Inhibitor (BPTI). Previous electrophysiological experiments in Xenopus leavis oocytes have shown that the kalicludines block $\mathrm{K}_{\mathrm{V}} 1.2$ channels with $\mathrm{IC}_{50}$ values around $1 \mu \mathrm{M}$. SHTX II was reported to inhibit the binding of ${ }^{125} \mathrm{I}-\alpha$-DTX to synaptosomal membranes with an $\mathrm{Kd}$ value of $650 \mathrm{nM}$ [21,22]. As shown in figure 3A, the pure peptide APEKTx1 was subject of a wide screening on 23 ion channels: 12 cloned voltage-gated potassium channels $\left(\mathrm{K}_{\mathrm{V}} 1.1-\mathrm{K}_{\mathrm{V}} 1.6, \mathrm{~K}_{\mathrm{V}} 1.1\right.$ mutant, $\mathrm{K}_{\mathrm{V}} 2.1, \mathrm{~K}_{\mathrm{V}} 3.1, \mathrm{~K}_{\mathrm{V}} 4.2, \mathrm{~K}_{\mathrm{V}} 4.3$, hERG, the insect channel Shaker IR); 2 cloned hyperpolarization-activated 
cyclic nucleotide-sensitive cation non-selective channels (HCN1 and HCN2) and 8 cloned voltage-gated sodium channels $\left(\mathrm{Na}_{\vee} 1.2-\mathrm{Na}_{\vee} 1.8\right.$ and the insect channel $\left.\mathrm{DmNa}_{\mathrm{V}} 1\right)$. Surprisingly, at concentrations up to 1 $\mu \mathrm{M}$, no significant effect could be observed on the other ion channel isoforms tested. Figure 3B shows original traces for wild type $\mathrm{K}_{\mathrm{V}} 1.1$ channels with application of $0.3,1$ and $3 \mathrm{nM}$ APEKTx 1 and for mutant $\mathrm{K}_{\mathrm{V}} 1.1$ channels with application of $100 \mu \mathrm{M}$ APEKTx1. A concentration response curve was constructed in order to determine the concentration at which half of the channels were blocked by APEKTx1. The $\mathrm{IC}_{50}$ value yielded $0.9 \pm 0.1 \mathrm{nM}$ (fig. 4A). Thus APEKTx1 inhibits $\mathrm{K}_{\mathrm{V}} 1.1$ channels with the same potency as DTX I and $\alpha$-DTX and is approximately 700 to 3000 times more potent than other known 2 sea anemone peptides directed against $\mathrm{K}_{\mathrm{V}}$ channels. Moreover, this also means that at concentrations which are a 1000 -fold the $\mathrm{IC}_{50}$ value of $\mathrm{APETx} 1$ on $\mathrm{K}_{\mathrm{V}} 1.1$, this toxin still discriminates between subtype isoforms.

The inhibition of $\mathrm{K}_{\mathrm{V}} 1.1$ channels by APEKTx 1 was not voltage-dependent as in a range of test potentials from $-30 \mathrm{mV}$ to $+40 \mathrm{mV}$ no difference in the degree of APEKTx1 induced block could be observed $(\mathrm{n}=8)$ (fig. 4B).

In order to investigate if the observed current inhibition is due to pore blockage or rather to altered channel gating upon APEKTx 1 binding, the $I V$ and $g V$ curves in ND96 and HK solution were constructed (fig. 4C and D). Application of $10 \mathrm{nM}$ APEKTX1 caused $80.45 \pm 2.23 \%$ and $84.21 \pm 3.74 \%$ inhibition of the potassium current in ND96 and HK, respectively (n=10). In ND96, the $g_{\max }$ curve in control and in the presence of $10 \mathrm{nM}$ toxin was characterized by a $\mathrm{V}_{1 / 2}$ value of $-15.7 \pm 1.23 \mathrm{mV}$ and $-12.71 \pm 0.5 \mathrm{mV}(\mathrm{n}=8)$ respectively. In $\mathrm{HK}$, the $\mathrm{V}_{1 / 2}$ was respectively, $-25.84 \pm 2.53 \mathrm{mV}$ and $-19.89 \pm 3.2 \mathrm{mV}(\mathrm{n}=8)$. It can be concluded that in both solutions no significant difference in $\mathrm{V}_{1 / 2}$ values occurred $(\mathrm{P}>0.05)$. Furthermore, the $I V$ relationship in $\mathrm{HK}$ solution shows that the reversal potential, $E_{K}$ is not significantly influenced by APEKTx1 $(\mathrm{P}>0.05 ; \mathrm{n}=8) . E_{K}$ values yielded $-7.56+/-2.45 \mathrm{mV}$ in control and $-7.96+/-1.92 \mathrm{mV}$ after application of toxin. All together, these experiments imply that current inhibition upon APEKTx1 binding does not result from changes in the voltage-dependence of channel gating. Presumably, APEKTx1 acts by blocking the pore in the open state of the $\mathrm{K}_{\mathrm{V}}$ channel.

Blockage of $K_{V} 1.1$ channels occurred rapidly and its binding was reversible since the current recovered quickly and completely upon washout $(\mathrm{n}=10)$ (fig. 4E). Both characteristics suggest an extracellular site of action. The reversibility of current inhibition is in contrast with DTX K binding. Toxin $\mathrm{K}$ binding is reversible at low concentrations but becomes irreversibly at concentrations higher than its $\mathrm{IC}_{50}$ value. However, alanine substitution of the Lys3 or Lys26 rendered DTX K binding reversible, possibly explaining the reversible binding of APEKTx1 since this toxin also possess neutral residues at these positions. Another observed difference between both toxins is that DTX K cannot fully inhibit the potassium current, even at very high concentrations. APEKTx1 however, is able to completely inhibit the current.

Because APEKTx1 did not alter channel gating and binding was reversible we investigated whether APEKTx1 blockage followed the kinetic behavior of a bimolecular reaction [23]. Figure 4F shows the effects of increasing concentrations APEKTx1 on a $\mathrm{K}_{\mathrm{V}} 1.1$ channel. The apparent first order association rate constant $\mathrm{k}_{\text {on }}$ (open circles) increased linearly with toxin concentration, while the second order dissociation constant $\mathrm{k}_{\text {off }}$ (closed circles) remained constant. Both values are in concordance with the scheme of a bimolecular reaction. The influence on toxin-channel binding by through-space electrostatic forces between charged residues of the $\mathrm{K}_{\mathrm{V}} 1.1$ channel and of APEKTx1 was also examined. This was done by measuring the effectiveness of APEKTx1 binding on $\mathrm{K}_{\mathrm{V}} 1.1$ channels in solutions of different ionic strength. As described above, the $\mathrm{IC}_{50}$ value of APEKTx 1 for $\mathrm{K}_{\mathrm{V}} 1.1$ homomeric channels was $0.9 \pm$ $0.1 \mathrm{nM}$. However, when using an iso-osmotic solution with a $48 \mathrm{mM} \mathrm{NaCl}$ concentration (sucrose substitution) the obtained $\mathrm{IC}_{50}$ value was $0.43 \pm 0.07 \mathrm{nM}$. This 2 fold increase in APEKTx1 potency underlines that through-space electrostatic interaction is involved in APEKTx1 binding. These results are in corroboration with previously described similar observations for charybdotoxin binding to Shaker channels and for $\alpha$-DTX binding to $\mathrm{K}_{\mathrm{V}} 1.1$ channels [23-25].

In order to define the $\alpha$-dendrotoxin footprint on mammalian potassium channels, 3 mutations (A352P, E353S and $\mathrm{Y} 379 \mathrm{H}$ ) were introduced in the dendrotoxin binding site, located in the H5 loop between the 
transmembrane domains $\mathrm{S} 5$ and $\mathrm{S} 6$ of $\mathrm{K}_{\mathrm{V}} 1.1$ subunits (fig. 5). By mutating these 3 particular residues, the pore region of the $\mathrm{K}_{\mathrm{V}} 1.1$ triple mutant closely resembles this one of $\mathrm{K}_{\mathrm{V}} 1.3$ channels [23,24]. We investigated whether the sensitivity of APEKTx 1 for $\mathrm{K}_{\mathrm{V}} 1.1$ could be affected by mutating these 3 critical residues. Interestingly, even at extreme high concentrations, APEKTx1 was unable to induce full blockage of current through these mutated $\mathrm{K}_{\mathrm{V}} 1.1$ channels. Application of $100 \mu \mathrm{M}$ APEKTx1 caused only $53 \%$ inhibition $(\mathrm{n}=4)$ and the obtained $\mathrm{IC}_{50}$ yielded $10.8 \pm 0.6 \mu \mathrm{M}$ (fig. $4 \mathrm{~A}$ and Fig. 3B). This dramatic loss of affinity underlines the crucial interaction of these mutated residues with the toxin. Since it was reported that DTX K only needs one $\mathrm{K}_{\mathrm{V}} 1.1$ subunit to cause inhibition of the potassium current through wild type heteromultimeric channels [26], we investigated also if DTX K could block the triple mutant. Concentration response curves were constructed for both $\mathrm{K}_{\mathrm{V}} 1.1$ wild type and triple mutant channels (fig. 4A). The observed $\mathrm{IC}_{50}$ value for wild type channels was $0.51 \pm 0.064 \mathrm{nM}$ which is in good accordance with previous reported values [27]. For mutant channels the $\mathrm{IC}_{50}$ was $5.28 \pm 0.23 \mathrm{nM}$. This means a 10-fold decrease in sensitivity compared to wild type channels.

\subsection{Trypsin inhibition activity.}

As all members of the type 2 sea anemone toxins APEKTx1 share sequence homology with the well characterized and potent Kunitz-type protease inhibitor BPTI, we also investigated if APEKTx1 could block trypsin activity. In order to do this, trypsin was incubated with different concentrations of APEKTx 1 at room temperature for 3 hours to reach equilibrium. In the same conditions, trypsin was also incubated with DTX I, DTX K or BPTI. The protease inhibition activity was determined spectrophotomatrically after incubation by measuring the ability of the remaining free trypsin to release paranitroaniline from BAPNA. It has been shown before that the kalicludines have a very similar inhibition profile as BPTI [21]. Figure 6 shows that APEKTx1 is a trypsin inhibitor with a $\mathrm{K}_{\mathrm{d}}=124 \mathrm{nM}$. Presumably, APEKTx1 is a competitive trypsin inhibitor. A 3-fold molecular excess of APEKTx1 over trypsin completely inhibited the paranitroanaline release. However, this is almost 3 times the amount of BPTI or the kalicludines necessary to reach total inhibition of trypsin activity. The same figure also indicates that DTX I and DTX K, could not inhibit the trypsin activity, even at a 6:1 ratio of toxin over trypsin.

\section{Discussion}

The unique feature of a dual functionality within one molecule is intriguing. However, since the production of toxins is an energy demanding task for an organism, the dual effects contained within one molecule can be seen as an efficient and economic manner to save energy with a maximal pharmacological output. Furthermore, the dual effect has clearly advantages for the sea anemone in both an offensive and defensive point of view: the presence of a trypsin inhibitor will prolong the half-life of the peptides in the venom and therefore optimize the strategy of the venom.

APEKTx1 is the newest member of the type 2 sea anemone toxins directed towards voltage-gated potassium channels. To date, this family exists of only 4 other toxins, 3 kalicludines and SHTX II. Although it is known that these toxins are effective on $\mathrm{K}_{\mathrm{V}}$ channels, little is known about their subtype selectivity. Here we report for the first time a screening of a type 2 toxin on a wide range of 23 different ion channels. This broad screening not only reveals a potent activity against $\mathrm{K}_{\mathrm{V}} 1.1\left(\mathrm{IC}_{50}=0.9 \pm 0.1 \mathrm{nM}\right)$ but also points out an impressive selectivity for these channels over the other isoforms tested. Even at concentrations 1000 -fold higher than the $\mathrm{IC}_{50}$ value for $\mathrm{K}_{\mathrm{V}} 1.1$ channels, APEKTx1 has the ability to selectively inhibit this isoform subtype over others within the $\mathrm{K}_{\mathrm{V}} 1$ family. Moreover, A352P, E353S and Y379H substitutions in the $K_{V} 1.1$ subunit made these channels insensitive for APEKTx1 indicating that these 3 residues are critical for the toxin-channel interaction. Further electrophysiological characterization showed that this toxin does not modulate the voltage dependence of gating of $\mathrm{K}_{\mathrm{V}}$ channels. The IV relationship in HK solution showed that ion selectivity was not changed after toxin binding. The observation that there is no difference in the percentage induced block either in ND96 or HK leads to the 
conclusion that channel blockage is independent of the direction of the potassium current flux and is not influenced by the extracellular concentration of $\mathrm{K}^{+}$ions. Moreover, APEKTx 1 did not show voltage dependence in its blockage of channels in a wide voltage range. The site of toxin binding is presumably located at the extracellular side since the inhibition of current through $\mathrm{K}_{\mathrm{V}} 1.1$ channels occurred rapidly and binding was reversible upon washout. We have shown that APEKTx1 shares not only sequence and structure homology with dendrotoxins (fig. 7) but also a similar activity profile with a comparable potency as these snake toxins. The APEKTx1 blockage followed the kinetic behavior of a bimolecular reaction as previously described for $\alpha$-DTX. The dendrotoxins have been extensively studied. The X-ray structure of $\alpha$-DTX and the NMR structure of DTX K have been reported [28,29]. They both possess structures which resemble very well the Kunitz-type serine protease inhibitors such as BPTI. The dendrotoxins have an $\mathrm{N}$-terminal $3_{10}$-helix, a $\beta$ hairpin and a $\mathrm{C}$-terminal $\alpha$-helix. The residues important for their potent $\mathrm{K}_{\mathrm{V}}$ blocking activity have been characterized. For DTX $\mathrm{K}$, site-directed mutagenesis studies have shown that Lys3, Tyr4, Lys6, Pro8, Arg10, Trp25, Lys26 and Lys28 are the main residues involved in the interaction with the $K_{V} 1.1$ channels [30-32]. Among these, the basic residues in the $3_{10^{-}}$ helix, Lys3 and Lys6, have been pointed out as the key residues for toxin binding since mutation to an alanine led to an dramatically decrease in the ability to inhibit the $\mathrm{K}^{+}$current [33]. Mutating the Pro8 and the $\operatorname{Arg} 10$ caused a 50- and 140-fold increase in $\mathrm{IC}_{50}$ value, respectively. The dramatic loss of affinity observed for DTX K binding to synaptic membranes when Trp25 and Lys26 were mutated to a alanine underlines that these residues are critical in recognition of $K_{V} 1.1$ channels [33,34]. Among these key residues, Pro8, Arg10 and Arg28 are conserved in APEKTx1.

For $\alpha$-DTX a mutational approach based on site-directed mutagenesis and chemical synthesis in which 31 out of 59 amino acids were mutated, revealed that Arg1, Arg2, Lys3, Leu4, Ile6, Leu7 were crucial for channel blockage activity of this toxin. Substituting Arg1 by alanine resulted in a less than 10-fold decreased affinity, whereas Arg2, Leu4 and Ile6 substitution lowered the affinity 10 to 30 times. The Lys 3 and Leu6 seem to be the most critical residues since mutating these amino acids resulted in a thousand times less potent toxins [30,31,35,36]. Of these residues critical for $\alpha$-DTX binding, the leu 4 and Ile6 are replaced by a homologous residue in APEKTx 1.

These Lys 3 and Leu6 residues in $\alpha$-DTX form the so-called dyad. It has been proposed that most toxins that block $\mathrm{K}_{\mathrm{V}}$ channels possess a conserved functional core composed of a key basic residue (Lys or Arg) associated with a $6.6 \pm 1 \AA$ distant key hydrophobic residue (Leu, Tyr or Phe). Such a functional dyad can be found in a broad range of structurally unrelated peptides from various animals such as scorpions, cone snails, snakes and sea anemones [37,38]. However, it has been reported that besides this dyad, other toxin determinants are required for a high affinity interaction between the toxin and his target [39]. Known examples of toxins lacking a dyad but still capable of blocking the $\mathrm{K}_{\mathrm{V}}$ channel (or the other way around toxins with a dyad but incapable of blocking) strongly suggest that the functional dyad on its own cannot represent the minimal pharmacophore or prerequisite for Kv1 binding [40,41]. Docking experiments with the scorpion toxin Pil and its homologs have highlighted that a ring of basic residues interacts with acidic residues of the $\mathrm{K}^{+}$channel turret located in the most extracellular part of the channel outer vestibule. Pi1 analogs, in which the basic residues from the ring were replaced by alanines, show a 50-480-fold reduction in peptide affinity for their target but were still able to block the potassium current [38]. In general, it is assumed that toxins recognize the Kv1 subtypes through the interaction of various toxin residues, among which the basic ring, with certain residues of the $\mathrm{K}_{\mathrm{V}} 1$ channel turret. These interactions can be sufficient to inhibit the potassium current. Moreover, these specific molecular contacts determine toxin selectivity towards particular $\mathrm{K}_{\mathrm{V}} 1$ channel isoforms. The functional dyad can then be viewed as a secondary anchoring point, providing a higher toxin affinity without altering toxin selectivity. The side chain of the basic key residue enters the ion channel pore and is surrounded by four Asp residues of the Ploop selectivity filter. This Asp residue is highly conserved among all the $\mathrm{K}_{\mathrm{V}} 1$ channel isoforms. The carbonyl oxygen atoms of these Asp residues will form a stabilizing interaction with the side chain of the basic residue of the dyad. The key hydrophobic residue of the dyad will interact through both hydrophobic forces and hydrogen bonding with a cluster of aromatic residues in the P-loop. The specific positioning of the 2 residues from the dyad results in a physical barrier, especially because of the 
positively charged side chain which is opposed to the $\mathrm{K}^{+}$flux $[42,43]$. Because of the low identity with other $\mathrm{K}_{\mathrm{V}}$ channel toxins and because none of the key residues critical for the $\mathrm{K}_{\mathrm{V}}$ blockage of DTX K or $\alpha$ DTX are conserved in APEKTx1, we tried to hypothesize the key residues of APEKTx1 with the help of structural models. As it can be seen from figure 7, the role of a possible dyad in APEKTx1 can be fulfilled by Arg15 and Phe13, a basic and hydrophobic residues which are $6.2 \AA$ separated. Assumably, the side chain of $\operatorname{Arg} 15$ enters the $\mathrm{K}_{\mathrm{V}} 1.1$ channel pore and interacts with the carbonyl oxygen atoms of the Asp377 residues. The Phe13 will most likely interact through hydrophobic forces with the aromatic cluster formed by Phe356, Trp364, Trp365, and Tyr375. Previous work has highlighted Tyr375 in $\mathrm{K}_{\mathrm{V}} 1.1$ as a crucial residue for the selectivity of scorpion and sea anemone toxins [44]. The amino acid at this position is highly variable between $\mathrm{K}_{\mathrm{V}} 1$ isoforms and the nature of the side chain of this residue contributes significantly to the subtype selectivity of toxins. The observed 12000 -fold decrease in affinity of APEKTx 1 for mutated $\mathrm{K}_{\mathrm{V}} 1.1$ channels can be explained partially by the $\mathrm{Y} 379 \mathrm{H}$ mutation. The same mutation prevented the $\mathrm{K}_{\mathrm{V}} 1.1$ binding of another sea anemone toxin $\mathrm{BgK}$, which binds to wild type channels with an $\mathrm{IC}_{50}$ value of $0.7 \mathrm{nM}$ [43-46]. The E353 also seems to be critical for interaction with APEKTx1. Hurst et al have shown that each of the 3 mutations on its own decreased dendrotoxin potency and that the removal of a negative charge at position 353 caused the greatest decrease in affinity [24]. However, simultaneous substitution of all 3 residues caused a much stronger decrease in DTX sensitivity than the single mutations. Further site-directed mutagenesis studies or ideally co-crystallization studies are required to elucidate if such subtle changes in sequence of the pore region are responsible for the dramatically loss of sensitivity of $\mathrm{K}_{\mathrm{V}} 1.1$ for this toxin.

Also shown in figure 7 are the basic residues which are conserved in DTX K and $\alpha$-DTX. These residues possibly contribute to the basic ring important for recognition, interaction and correct positioning of the toxin on the channel. As mentioned above, previous work has shown that mutating these conserved residues leads to affinity loss in DTX K or $\alpha$-DTX [30]. However, this is only a hypothesis which requires further conformation from site-directed mutagenesis studies, docking experiments and structure analysis. The bovine pancreatic trypsin inhibitor belongs to the Kunitz-type inhibitors and is a potent inhibitor of serine proteases. The crystal structures of BPTI with bovine trypsin and with bovine chymotrypsin have been determined [47-49]. Analysis of these complexes have shown that there are 10-13 residues on the inhibitor forming less than $4 \AA$ contacts with 20-25 residues of the enzyme. The 13 key residues of the inhibitor form a structural epitope seen as two extended and exposed loops. The first loop which is the primary contact site is composed of the residues Thr11 to Ile19. The second loop is more C-terminal situated and is formed by residues Gly36 to Arg39 [50,51]. The Lys15 has been pinpointed as a single residue hot spot responsible for a major part of the enzyme-inhibitor contacts. The side chain of this basic amino acid penetrates deeply into the specificity binding pocket of the protease where it electrostaticly interacts with the Asp189 of the protease. This Lys15-Asp189 interaction delivers the major contribution to the association energy for the BPTI-trypsin complex. The role of Lys15 as a crucial player in the energetics of the recognition was demonstrated by substituting this residue with Gly. The point mutation reduced the total association energy with $70 \%$ leading to an association constant decreased by 9 orders of magnitude. Structure determination of $\alpha$-DTX provided an explanation why this toxin and its homologue DTX I cannot inhibit proteases. The basic amino acid in BPTI has been replaced in $\alpha$-DTX by a Tyr incapable of interacting effectively with binding pocket of trypsin [52-54]. Further explanation for the lack of protease inhibition by the dendrotoxins can be found in the presence of Asp17 in $\alpha$-DTX, Glu17 in DTX I and Arg16 in DTX K. The existence of these longer amino acid residues in dendrotoxins instead of the smaller alanine in BPTI causes a most unfavorable complex with the trypsin binding site. Moreover, the Pro19 in DTX K and Pro21 in DTX I and $\alpha$-DTX instead of the Ile19 in BPTI greatly impedes a good interaction with the side chain of the Tyr39 of trypsin. The residues essential for kunitz-type inhibition in the primary contact site (Gly12, Cys14, Lys15 and Ala16) are all conserved in APEKTx1 except for the Arg15 (fig. 7). However, previous residue-specific modification studies have shown that mutating the Lys 15 to Arg did not alter the association constant. The lower protease inhibition activity of APEKTx 1 compared to BPTI (fig.5) can be explained by the presence of Phe13 and Pro19. A double BPTI mutant with a phenylalanine at position 13 and an arginine at position 15, exactly as in APEKTx1, resulted in a 
100-fold decreased association constant compared to the wild type [54]. The unfavorable interaction of Pro19 with trypsin has been described above.

\section{Conclusion}

We have demonstrated the unique dual function of APEKTx1, which is a competitive Kunitz-type protease inhibitor and a very potent and selective $\mathrm{K}_{\mathrm{V}} 1.1$ channel blocker. Moreover, several amino acid residues have been suggested to play a functionally critical role in the high potency and unique selectivity of this toxin. Further structure-function analysis involving site-directed mutagenesis studies, docking experiments and NMR are required in order to confirm their role. Because of its high affinity and selectivity, APEKTx1 might be a very interesting probe for further characterization of the binding sites of $\mathrm{K}_{\mathrm{V}} 1.1$ channels. Finally, APEKTx 1 represents a valuable tool to examine the exact role of $\mathrm{K}_{\mathrm{V}} 1.1$ in various channelopathies, and might serve as a lead compound in the development of novel therapeutical agents for these diseases.

Acknowledgments We would like to thank O. Pongs for sharing the $\mathrm{rK}_{\mathrm{V}} 1.2, \mathrm{rK}_{\mathrm{V}} 1.4$, and $\mathrm{rKV} 1.5$ and $\mathrm{rK}_{\mathrm{V}} 1.6 \mathrm{cDNA}$. We are grateful to M.L. Garcia for sharing the $\mathrm{hK}_{\mathrm{V}} 1.3$ clone and to DJ Snyders for sharing the $\mathrm{rK}_{\mathrm{V}} 2.1, \mathrm{hK}_{\mathrm{V}} 3.1, \mathrm{rKV} 4.2$ and $\mathrm{rK}_{\mathrm{V}} 4.3$. The Shaker IR clone was kindly provided by G. Yellen. We thank M. Keating for sharing hERG, John N. Wood for sharing rNa 1.8 , A.L. Goldin for sharing rNa 1.2 , $\mathrm{rNa}_{\mathrm{v}} 1.3$ and $\mathrm{mNa}_{\mathrm{v}} 1.6$, G. Mandel for sharing $\mathrm{rNa}_{\mathrm{v}} 1.4$, R.G. Kallen for sharing $\mathrm{hNa} \mathrm{v}_{\mathrm{v}} 1.5$, S.H. Heinemann for sharing the rat $\beta 1$ subunit, S.C. Cannon for sharing the $\mathrm{h} \beta 1$ subunit and Martin S. Williamson for providing the Para and tipE clone. The $\mathrm{Na}_{\mathrm{v}} 1.7$ clone was kindly provided by Roche. The authors would like to thank Prof. Dr. Dr.h.c. Wolf-Georg Forssmann, Dr. Eva Cuypers for the useful discussions, Dr. Elia Diego-García for helpful suggestions and Annelies Van Der Haegen for help with the modeling. This work was supported by the following grants: G.0257.08 and G.0330.06 (F.W.O. Vlaanderen), OT-05-64 (K.U. Leuven), UA P6/31 (IAP), P6/28 (IAP), GOA 08/16 (K.U.Leuven).

Conflict of interest The authors declare that they have no conflict of interest.

\section{Reference}

[1] Gutman, G.A., Chandy, K.G., Grissmer, S., Lazdunski, M., McKinnon, D., Pardo, L.A., Robertson, G.A., Rudy, B., Sanguinetti, M.C., Stuhmer, W. and Wang, X., International Union of Pharmacology. LIII. Nomenclature and molecular relationships of voltage-gated potassium channels, Pharmacol Rev 57 (2005) 473-508.

[2] Lujan, R., Organisation of potassium channels on the neuronal surface, J Chem Neuroanat 40 (2010) 1-20.

[3] Yu, F.H., Yarov-Yarovoy, V., Gutman, G.A. and Catterall, W.A., Overview of molecular relationships in the voltage-gated ion channel superfamily, Pharmacol Rev 57 (2005) 387-395.

[4] Pongs, O., Voltage-gated potassium channels: from hyperexcitability to excitement, FEBS Lett 452 (1999) 31-35.

[5] Bezanilla, F., The voltage sensor in voltage-dependent ion channels, Physiol Rev 80 (2000) 555592.

[6] Swartz, K.J., Towards a structural view of gating in potassium channels, Nat Rev Neurosci 5 (2004) 905-916.

[7] Jiang, B., Sun, X., Cao, K. and Wang, R., Endogenous Kv channels in human embryonic kidney (HEK-293) cells, Mol Cell Biochem 238 (2002) 69-79.

[8] Ouadid-Ahidouch, H., Chaussade, F., Roudbaraki, M., Slomianny, C., Dewailly, E., Delcourt, P. and Prevarskaya, N., KV1.1 K(+) channels identification in human breast carcinoma cells: involvement in cell proliferation, Biochem Biophys Res Commun 278 (2000) 272-277. 
[9] Andreev, Y.A., Kozlov, S.A., Koshelev, S.G., Ivanova, E.A., Monastyrnaya, M.M., Kozlovskaya, E.P. and Grishin, E.V., Analgesic compound from sea anemone Heteractis crispa is the first polypeptide inhibitor of vanilloid receptor 1 (TRPV1), J Biol Chem 283 (2008) 23914-23921.

[10] Honma, T. and Shiomi, K., Peptide toxins in sea anemones: structural and functional aspects, Mar Biotechnol (NY) 8 (2006) 1-10.

[11] Castaneda, O. and Harvey, A.L., Discovery and characterization of cnidarian peptide toxins that affect neuronal potassium ion channels, Toxicon 54 (2009) 1119-1124.

[12] Bosmans, F. and Tytgat, J., Sea anemone venom as a source of insecticidal peptides acting on voltage-gated $\mathrm{Na}+$ channels, Toxicon 49 (2007) 550-560.

[13] Oliveira, J.S., Zaharenko, A.J., Ferreira, W.A., Jr., Konno, K., Shida, C.S., Richardson, M., Lucio, A.D., Beirao, P.S. and de Freitas, J.C., BcIV, a new paralyzing peptide obtained from the venom of the sea anemone Bunodosoma caissarum. A comparison with the $\mathrm{Na}+$ channel toxin BcIII, Biochim Biophys Acta 1764 (2006) 1592-1600.

[14] Diochot, S. and Lazdunski, M., Sea anemone toxins affecting potassium channels, Prog Mol Subcell Biol 46 (2009) 99-122.

[15] Diochot, S., Baron, A., Rash, L.D., Deval, E., Escoubas, P., Scarzello, S., Salinas, M. and Lazdunski, M., A new sea anemone peptide, APETx2, inhibits ASIC3, a major acid-sensitive channel in sensory neurons, Embo J 23 (2004) 1516-1525.

[16] Bruhn, T., Schaller, C., Schulze, C., Sanchez-Rodriguez, J., Dannmeier, C., Ravens, U., Heubach, J.F., Eckhardt, K., Schmidtmayer, J., Schmidt, H., Aneiros, A., Wachter, E. and Beress, L., Isolation and characterisation of five neurotoxic and cardiotoxic polypeptides from the sea anemone Anthopleura elegantissima, Toxicon 39 (2001) 693-702.

[17] Diochot, S., Loret, E., Bruhn, T., Beress, L. and Lazdunski, M., APETx1, a new toxin from the sea anemone Anthopleura elegantissima, blocks voltage-gated human ether-a-go-go-related gene potassium channels, Mol Pharmacol 64 (2003) 59-69.

[18] Salceda, E., Garateix, A., Aneiros, A., Salazar, H., Lopez, O. and Soto, E., Effects of ApC, a sea anemone toxin, on sodium currents of mammalian neurons, Brain Res 1110 (2006) 136-143.

[19] Schaller, H.C. and Bodenmuller, H., Isolation and amino acid sequence of a morphogenetic peptide from hydra, Proc Natl Acad Sci U S A 78 (1981) 7000-7004.

[20] Liman, E.R., Tytgat, J. and Hess, P., Subunit stoichiometry of a mammalian K+ channel determined by construction of multimeric cDNAs, Neuron 9 (1992) 861-871.

[21] Schweitz, H., Bruhn, T., Guillemare, E., Moinier, D., Lancelin, J.M., Beress, L. and Lazdunski, M., Kalicludines and kaliseptine. Two different classes of sea anemone toxins for voltage sensitive K+ channels, J Biol Chem 270 (1995) 25121-25126.

[22] Honma, T., Kawahata, S., Ishida, M., Nagai, H., Nagashima, Y. and Shiomi, K., Novel peptide toxins from the sea anemone Stichodactyla haddoni, Peptides 29 (2008) 536-544.

[23] Tytgat, J., Debont, T., Carmeliet, E. and Daenens, P., The alpha-dendrotoxin footprint on a mammalian potassium channel, J Biol Chem 270 (1995) 24776-24781.

[24] Hurst, R.S., Busch, A.E., Kavanaugh, M.P., Osborne, P.B., North, R.A. and Adelman, J.P., Identification of amino acid residues involved in dendrotoxin block of rat voltage-dependent potassium channels, Mol Pharmacol 40 (1991) 572-576.

[25] MacKinnon, R. and Miller, C., Mutant potassium channels with altered binding of charybdotoxin, a pore-blocking peptide inhibitor, Science 245 (1989) 1382-1385.

[26] Akhtar, S., Shamotienko, O., Papakosta, M., Ali, F. and Dolly, J.O., Characteristics of brain Kv1 channels tailored to mimic native counterparts by tandem linkage of alpha subunits: implications for K+ channelopathies, J Biol Chem 277 (2002) 16376-16382.

[27] Robertson, B., Owen, D., Stow, J., Butler, C. and Newland, C., Novel effects of dendrotoxin homologues on subtypes of mammalian Kv1 potassium channels expressed in Xenopus oocytes, FEBS Lett 383 (1996) 26-30. 
[28] Skarzynski, T., Crystal structure of alpha-dendrotoxin from the green mamba venom and its comparison with the structure of bovine pancreatic trypsin inhibitor, J Mol Biol 224 (1992) 671683.

[29] Berndt, K.D., Guntert, P. and Wuthrich, K., Nuclear magnetic resonance solution structure of dendrotoxin K from the venom of Dendroaspis polylepis polylepis, J Mol Biol 234 (1993) 735750 .

[30] Harvey, A.L. and Robertson, B., Dendrotoxins: structure-activity relationships and effects on potassium ion channels, Curr Med Chem 11 (2004) 3065-3072.

[31] Gasparini, S., Danse, J.M., Lecoq, A., Pinkasfeld, S., Zinn-Justin, S., Young, L.C., de Medeiros, C.C., Rowan, E.G., Harvey, A.L. and Menez, A., Delineation of the functional site of alphadendrotoxin. The functional topographies of dendrotoxins are different but share a conserved core with those of other Kv1 potassium channel-blocking toxins, J Biol Chem 273 (1998) 2539325403.

[32] Imredy, J.P. and MacKinnon, R., Energetic and structural interactions between delta-dendrotoxin and a voltage-gated potassium channel, J Mol Biol 296 (2000) 1283-1294.

[33] Wang, F.C., Bell, N., Reid, P., Smith, L.A., McIntosh, P., Robertson, B. and Dolly, J.O., Identification of residues in dendrotoxin $\mathrm{K}$ responsible for its discrimination between neuronal K+ channels containing Kv1.1 and 1.2 alpha subunits, Eur J Biochem 263 (1999) 222-229.

[34] Smith, L.A., Reid, P.F., Wang, F.C., Parcej, D.N., Schmidt, J.J., Olson, M.A. and Dolly, J.O., Site-directed mutagenesis of dendrotoxin K reveals amino acids critical for its interaction with neuronal K+ channels, Biochemistry 36 (1997) 7690-7696.

[35] Danse, J.M., Rowan, E.G., Gasparini, S., Ducancel, F., Vatanpour, H., Young, L.C., Poorheidari, G., Lajeunesse, E., Drevet, P., Menez, R. and et al., On the site by which alpha-dendrotoxin binds to voltage-dependent potassium channels: site-directed mutagenesis reveals that the lysine triplet 28-30 is not essential for binding, FEBS Lett 356 (1994) 153-158.

[36] Harvey, A.L., Recent studies on dendrotoxins and potassium ion channels, Gen Pharmacol 28 (1997) 7-12.

[37] Dauplais, M., Lecoq, A., Song, J., Cotton, J., Jamin, N., Gilquin, B., Roumestand, C., Vita, C., de Medeiros, C.L., Rowan, E.G., Harvey, A.L. and Menez, A., On the convergent evolution of animal toxins. Conservation of a diad of functional residues in potassium channel-blocking toxins with unrelated structures, J Biol Chem 272 (1997) 4302-4309.

[38] Mouhat, S., Mosbah, A., Visan, V., Wulff, H., Delepierre, M., Darbon, H., Grissmer, S., De Waard, M. and Sabatier, J.M., The 'functional' dyad of scorpion toxin Pi1 is not itself a prerequisite for toxin binding to the voltage-gated Kv1.2 potassium channels, Biochem J 377 (2004) 25-36.

[39] MacKinnon, R., Cohen, S.L., Kuo, A., Lee, A. and Chait, B.T., Structural conservation in prokaryotic and eukaryotic potassium channels, Science 280 (1998) 106-109.

[40] Shon, K.J., Stocker, M., Terlau, H., Stuhmer, W., Jacobsen, R., Walker, C., Grilley, M., Watkins, M., Hillyard, D.R., Gray, W.R. and Olivera, B.M., kappa-Conotoxin PVIIA is a peptide inhibiting the shaker K+ channel, J Biol Chem 273 (1998) 33-38.

[41] Huys, I., Xu, C.Q., Wang, C.Z., Vacher, H., Martin-Eauclaire, M.F., Chi, C.W. and Tytgat, J., BmTx3, a scorpion toxin with two putative functional faces separately active on A-type $\mathrm{K}+$ and HERG currents, Biochem J 378 (2004) 745-752.

[42] Mouhat, S., De Waard, M. and Sabatier, J.M., Contribution of the functional dyad of animal toxins acting on voltage-gated Kv1-type channels, J Pept Sci 11 (2005) 65-68.

[43] Jouirou, B., Mouhat, S., Andreotti, N., De Waard, M. and Sabatier, J.M., Toxin determinants required for interaction with voltage-gated K+ channels, Toxicon 43 (2004) 909-914.

[44] Gilquin, B., Braud, S., Eriksson, M.A., Roux, B., Bailey, T.D., Priest, B.T., Garcia, M.L., Menez, A. and Gasparini, S., A variable residue in the pore of Kv1 channels is critical for the high affinity of blockers from sea anemones and scorpions, J Biol Chem 280 (2005) 27093-27102. 
[45] Visan, V., Fajloun, Z., Sabatier, J.M. and Grissmer, S., Mapping of maurotoxin binding sites on hKv1.2, hKv1.3, and hIKCa1 channels, Mol Pharmacol 66 (2004) 1103-1112.

[46] Alessandri-Haber, N., Lecoq, A., Gasparini, S., Grangier-Macmath, G., Jacquet, G., Harvey, A.L., de Medeiros, C., Rowan, E.G., Gola, M., Menez, A. and Crest, M., Mapping the functional anatomy of $\mathrm{BgK}$ on $\mathrm{Kv} 1.1, \mathrm{Kv} 1.2$, and $\mathrm{Kv} 1.3$. Clues to design analogs with enhanced selectivity, J Biol Chem 274 (1999) 35653-35661.

[47] Helland, R., Otlewski, J., Sundheim, O., Dadlez, M. and Smalas, A.O., The crystal structures of the complexes between bovine beta-trypsin and ten P1 variants of BPTI, J Mol Biol 287 (1999) 923-942.

[48] Capasso, C., Rizzi, M., Menegatti, E., Ascenzi, P. and Bolognesi, M., Crystal structure of the bovine alpha-chymotrypsin:Kunitz inhibitor complex. An example of multiple protein:protein recognition sites, J Mol Recognit 10 (1997) 26-35.

[49] Scheidig, A.J., Hynes, T.R., Pelletier, L.A., Wells, J.A. and Kossiakoff, A.A., Crystal structures of bovine chymotrypsin and trypsin complexed to the inhibitor domain of Alzheimer's amyloid beta-protein precursor (APPI) and basic pancreatic trypsin inhibitor (BPTI): engineering of inhibitors with altered specificities, Protein Sci 6 (1997) 1806-1824.

[50] Krowarsch, D., Dadlez, M., Buczek, O., Krokoszynska, I., Smalas, A.O. and Otlewski, J., Interscaffolding additivity: binding of $\mathrm{P} 1$ variants of bovine pancreatic trypsin inhibitor to four serine proteases, J Mol Biol 289 (1999) 175-186.

[51] Buczek, O., Koscielska-Kasprzak, K., Krowarsch, D., Dadlez, M. and Otlewski, J., Analysis of serine proteinase-inhibitor interaction by alanine shaving, Protein Sci 11 (2002) 806-819.

[52] Czapinska, H. and Otlewski, J., Structural and energetic determinants of the S1-site specificity in serine proteases, Eur J Biochem 260 (1999) 571-595.

[53] Lancelin, J.M., Foray, M.F., Poncin, M., Hollecker, M. and Marion, D., Proteinase inhibitor homologues as potassium channel blockers, Nat Struct Biol 1 (1994) 246-250.

[54] Krowarsch, D. and Otlewski, J., Amino-acid substitutions at the fully exposed P1 site of bovine pancreatic trypsin inhibitor affect its stability, Protein Sci 10 (2001) 715-724.

\section{Footnotes}

${ }^{\S}$ To whom correspondence should be addressed. Tel.: +32 163234 03; Fax: +32 163234 05; E-mail: jan.tytgat@pharm.kuleuven.be

The abbreviations used are: APEKTx1, Anthopleura elegantissime potassium channel toxin 1; MALDI TOF, matrix-assisted laser desorption-ionization time of flight; RP-HPLC, reversed-phase high performance liquid chromatography; TFA, trifluoroacetic acid; $\mathrm{K}_{\mathrm{V}}$ channel, voltage-gated potassium channel; DTX; dendrotoxin; BPTI, bovine pancreatic trypsin inhibitor.

\section{Figure Legends}

\section{Fig. 1: Purification of APEKTx1.}

A, the crude fraction found to be active in the electrophysiological screening was loaded on a C18 column with a linear gradient of $0.085 \%$ TFA in acetonitrile. Only the fraction containing the largest peak indicated by the arrow was active on $\mathrm{K}_{\mathrm{V}} 1.1$ channels. B, this active fraction was further purified using the same conditions as in A.

Fig. 2: Alignment.

Amino acid sequence of APEKTx1 and alignment with the other members of the type 2 sea anemone toxins, dendrotoxins, protease inhibitors from sea anemones and BPTI. Amino acid residues identical with APEKTx1 are shown on grey background, cysteine residues are printed in red. Disulfide bridge pattern based on AsKC3 are indicated. AsKC1-3 from Anemonia sulcata, AFAPI-I and AFAPI-III from Anthopleura fuscoviridis, AXPI-II from Anthopleura xanthogrammica, DTX E from Dendroaspis 


\section{polylepis polylepis, SHTX III from Stichodactyla haddoni, DTX K from Dendroaspis polylepis, $\alpha$-DTX} from and BPTI from Bos taurus.

Fig. 3: Activity of APEKTx1 on $K_{V}$ channels.

A, Differential effects of APEKTx1 on several cloned voltage gated potassium and sodium channel isoforms expressed in X. laevis oocytes. Representative whole-cell current traces in control and toxin conditions are shown. The dotted line indicates the zero-current level. The asterisk $(*)$ marks steady-state current traces after application of $1 \mu \mathrm{M}$ of APEKTx1. This screening on a large number of $\mathrm{K}_{\mathrm{V}}$ channel isoforms belonging to different subfamilies of the voltage gated potassium channel family shows that APEKTx 1 selectively blocks $\mathrm{K}_{\mathrm{V}} 1.1$ channels at a concentration of $1 \mu \mathrm{M}$. Traces shown are representative traces of at least 3 independent experiments $(n \geq 3)$.

$\mathrm{B}$, Original traces for wild type $\mathrm{K}_{\mathrm{V}} 1.1$ channels with application of $0.3,1$ and $3 \mathrm{nM}$ APEKTx 1 . For mutant $\mathrm{K}_{\mathrm{V}} 1.1$ channels original traces with application of $100 \mu \mathrm{M}$ APEKTx1 are also shown.

\section{Fig. 4: Effects on $K_{V} 1.1$ channel gating.}

A, dose-response curve on wild-type (closed symbols) and triple mutant (open symbols) $\mathrm{K}_{\mathrm{V}} 1.1$ channels obtained by plotting the percentage blocked current as a function of increasing toxin concentrations. For APEKTx1 (triangles), $\mathrm{IC}_{50}$ values yielded $0.9 \pm 0.1 \mathrm{nM}$ and $10.8 \pm 0.6 \mu \mathrm{M}$ for wild type and mutant channels, respectively. For DTX K (squares), $\mathrm{IC}_{50}$ values were determined at $0.51 \pm 0.064 \mathrm{nM}$ and $5.28 \pm$ $0.2 \mathrm{nM}$ for wild-type and mutant channels, respectively.

$\mathrm{B}$, the percentage of residual current after application of $10 \mathrm{nM}$ APEKTx 1 as a function of membrane potential. In a range of test potentials from $-30 \mathrm{mV}$ to $+40 \mathrm{mV}$, no difference in the degree of APEKTx 1 induced block could be observed.

$\mathrm{C}$ and D, show $I V$ and $g V$ curves in ND96 and HK respectively. APEKTx 1 does not act as a gating modifier. In ND96, the $\mathrm{V}_{1 / 2}$ in control (open circles) and in the presence of $10 \mathrm{nM}$ APEKTx1 (closed circles) was characterized by a value of $-15.7 \pm 1.23 \mathrm{mV}(\mathrm{n}=5)$ and $-12.71 \pm 0.5 \mathrm{mV}(\mathrm{n}=6)$ respectively. In $\mathrm{HK}$, the $\mathrm{V}_{1 / 2}$ yielded respectively, $-25.84 \pm 2.53 \mathrm{mV}$ and $-19.89 \pm 3.2 \mathrm{mV}$. No significant shift was observed. Moreover, APEKTx1 did not significantly alter the reversal potential. $\mathrm{E}$, fast kinetics of inhibition of $\mathrm{K}_{\mathrm{V}} 1.1$ channels and reversibility of the inhibition upon washout. Control (open triangles), wash-in, (open triangles+ black bar), wash-out (open circles). Values for $\tau_{\text {on }}$ and $\tau_{\text {off }}$ in this experiment were 92.7 and $47 \mathrm{~s}$, respectively.

F, APEKTx 1 blockage followed the kinetic behavior of a bimolecular reaction as proposed by Tytgat $e t$ $a l$. Displayed are the effects of increasing concentrations APEKTx1 on a $K_{V} 1.1$ channel. The apparent first order association rate constant $\mathrm{k}_{\text {on }}$ (open circles) increased linearly with the toxin concentration. The second order dissociation constant $\mathrm{k}_{\text {off }}$ (closed circles) remained constant. Both these values are in correlation with the scheme of a bimolecular reaction.

Fig. 5:.Alignment of the pore regions of $K_{V} 1$ family.

Sequence alignment of the pore region of $\mathrm{K}_{\mathrm{V}} 1.1-\mathrm{K}_{\mathrm{V}} 1.6$ and the $\mathrm{K}_{\mathrm{V}} 1.1$ mutant. The 3 mutated residues (A352P, E353S and $\mathrm{Y} 379 \mathrm{H}$ ) in the $\mathrm{K}_{\mathrm{V}} 1.1$ mutant are shown in red. Asp377, important for stabilizing the side chain of the basic residue of the dyad is shown in blue while the residue from the aromatic cluster (Phe356, Trp364, Trp365, Tyr375) which interacts with the hydrophobic residue of the dyad are shown in green.

\section{Fig. 6: Kunitz-type protease inhibition.}

The figure shows the concentration dependence of trypsin inhibition by different concentrations of BPTI, closed circles; APEKTx1, open circles; DTX I, open triangles and DTX K, open squares. A 3-fold molecular excess of APEKTx1 over trypsin inhibited the paranitroanaline release completely

Fig. 7: Spatial structure models of $\alpha$-DTX, DTX K, BPTI and APEKTx1. Structural models for $\alpha$-DTX (PDB accession code 1DTX), DTX K (1DTK), BPTI (1PIT) and APEKTx1. The model of APEKTx1 was built on the basis of the structure of the homologue snake protease inhibitor textilinin (3BYB). Residues known to be important for $\mathrm{K}_{\mathrm{V}}$ channel blockade ( $\alpha$-DTX, DTX K, APEKTx1) are indicated in red. The model for APEKTx1 shows the residues possibly forming a dyad in red, the residues possibly contributing to the basic ring are shown in green. The residues known to be 
1

2

3 important for protease inhibition (BPTI and APEKTx1) are colored in blue (primary contact site) and in yellow (secondary contact site). 
A

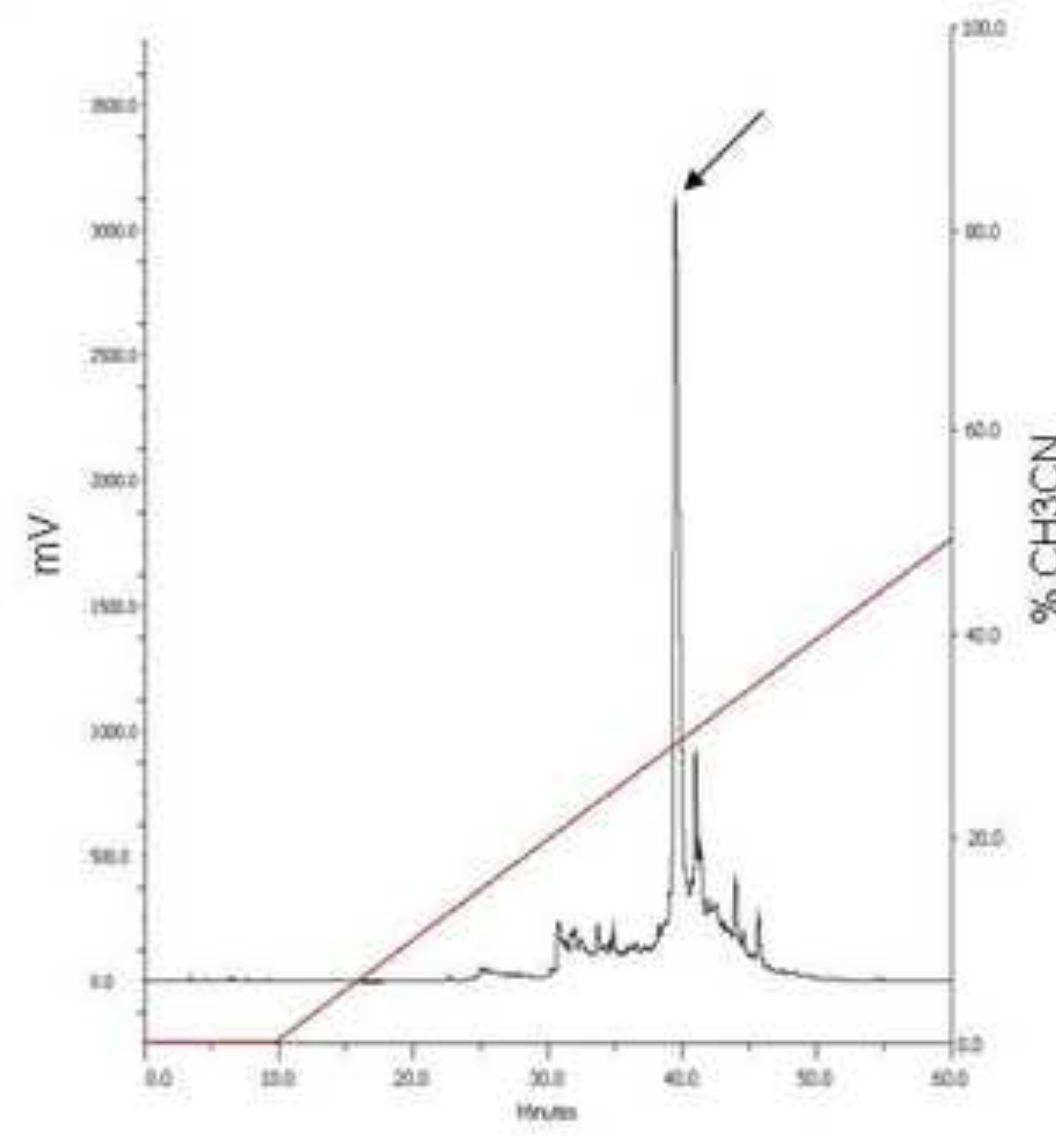

B

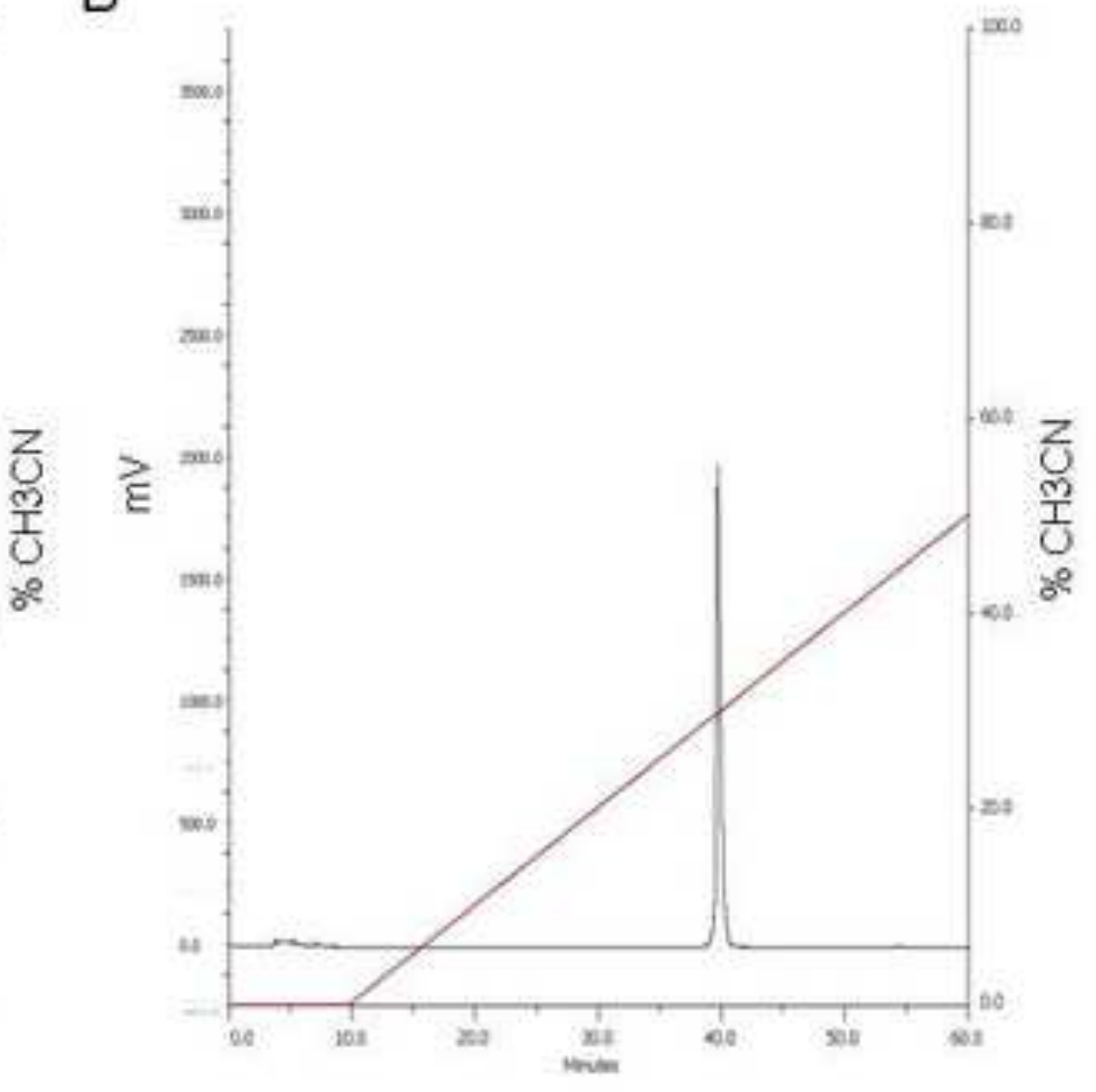


A

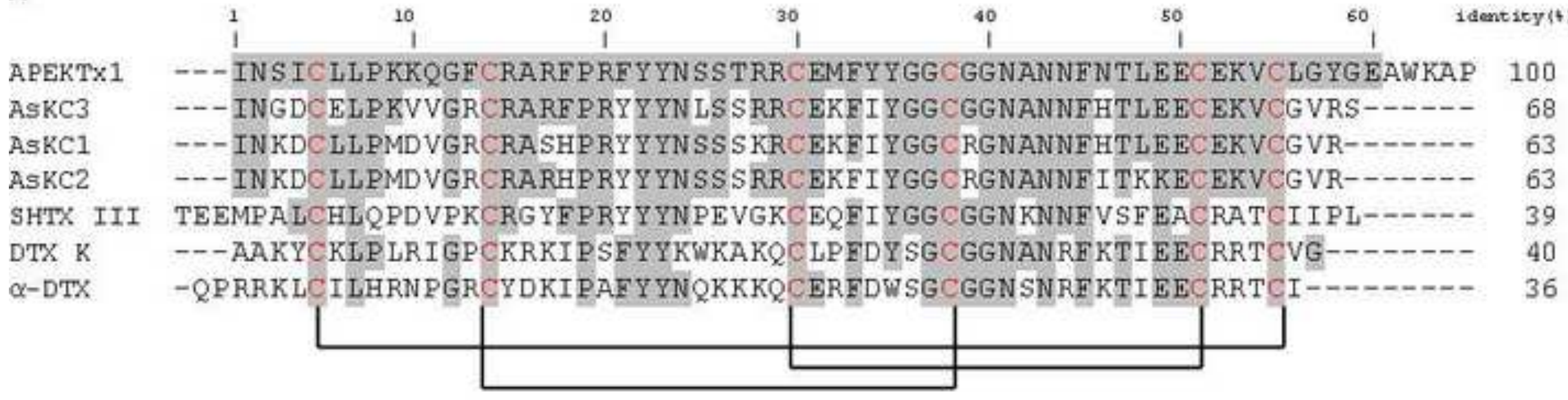
B

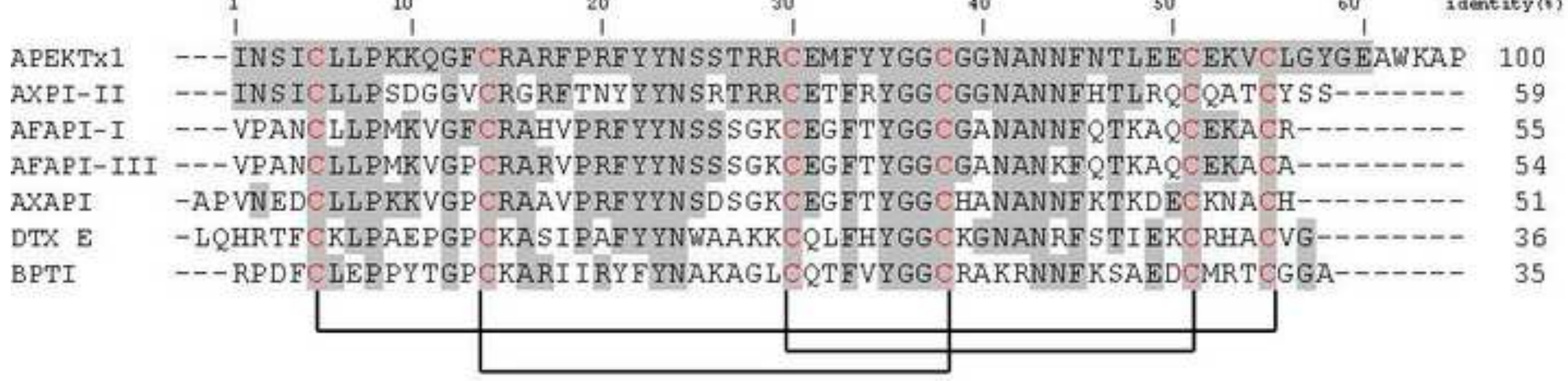




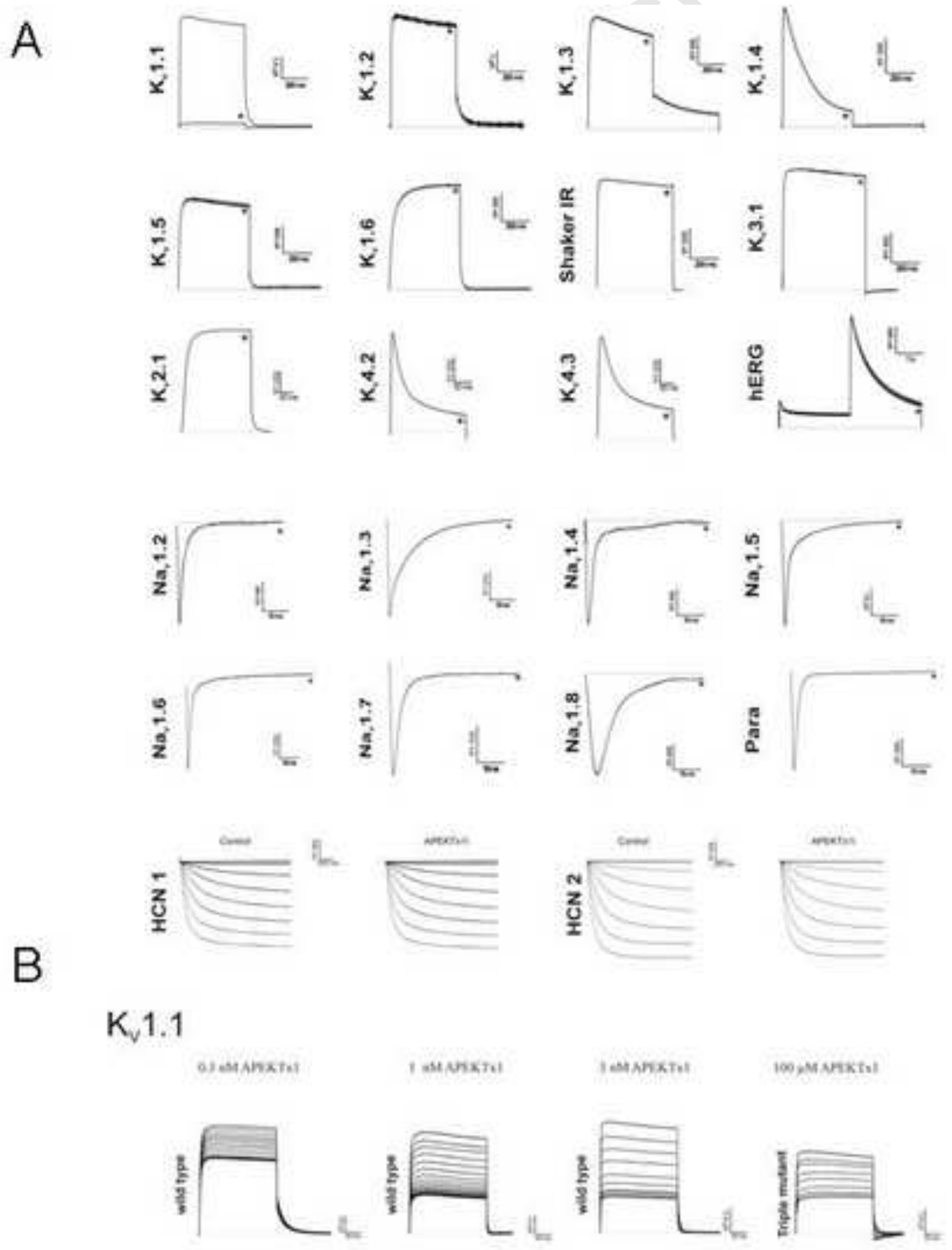



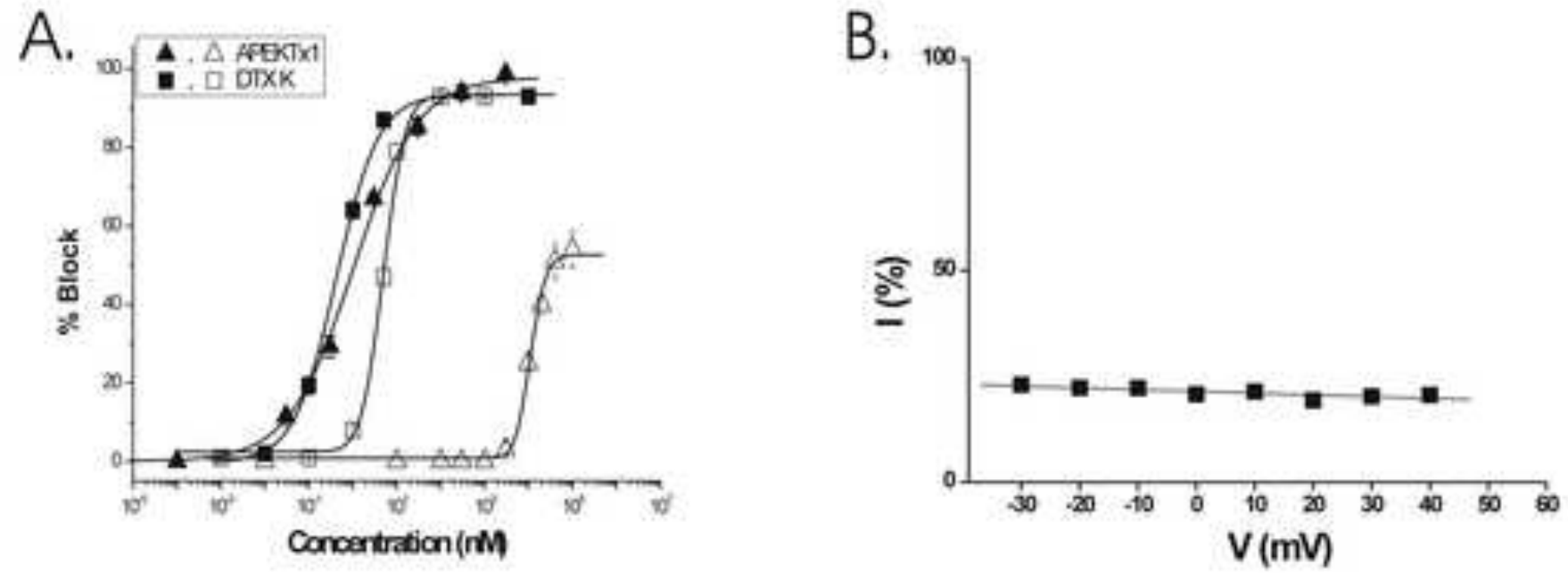

C.

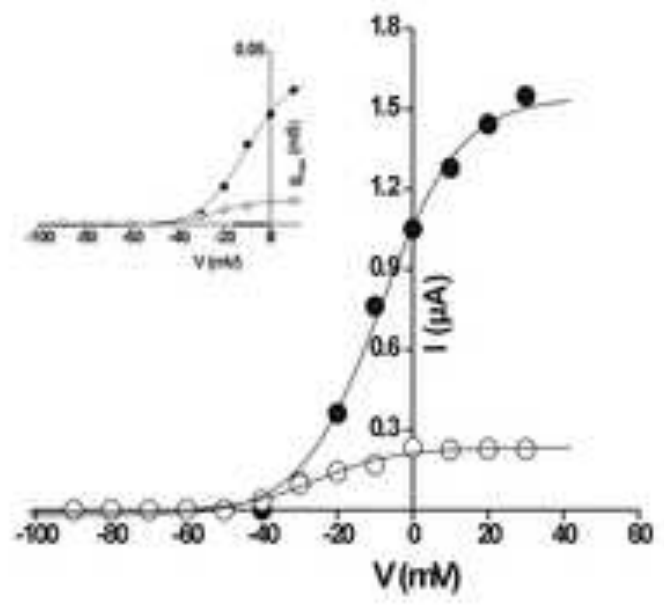

D.
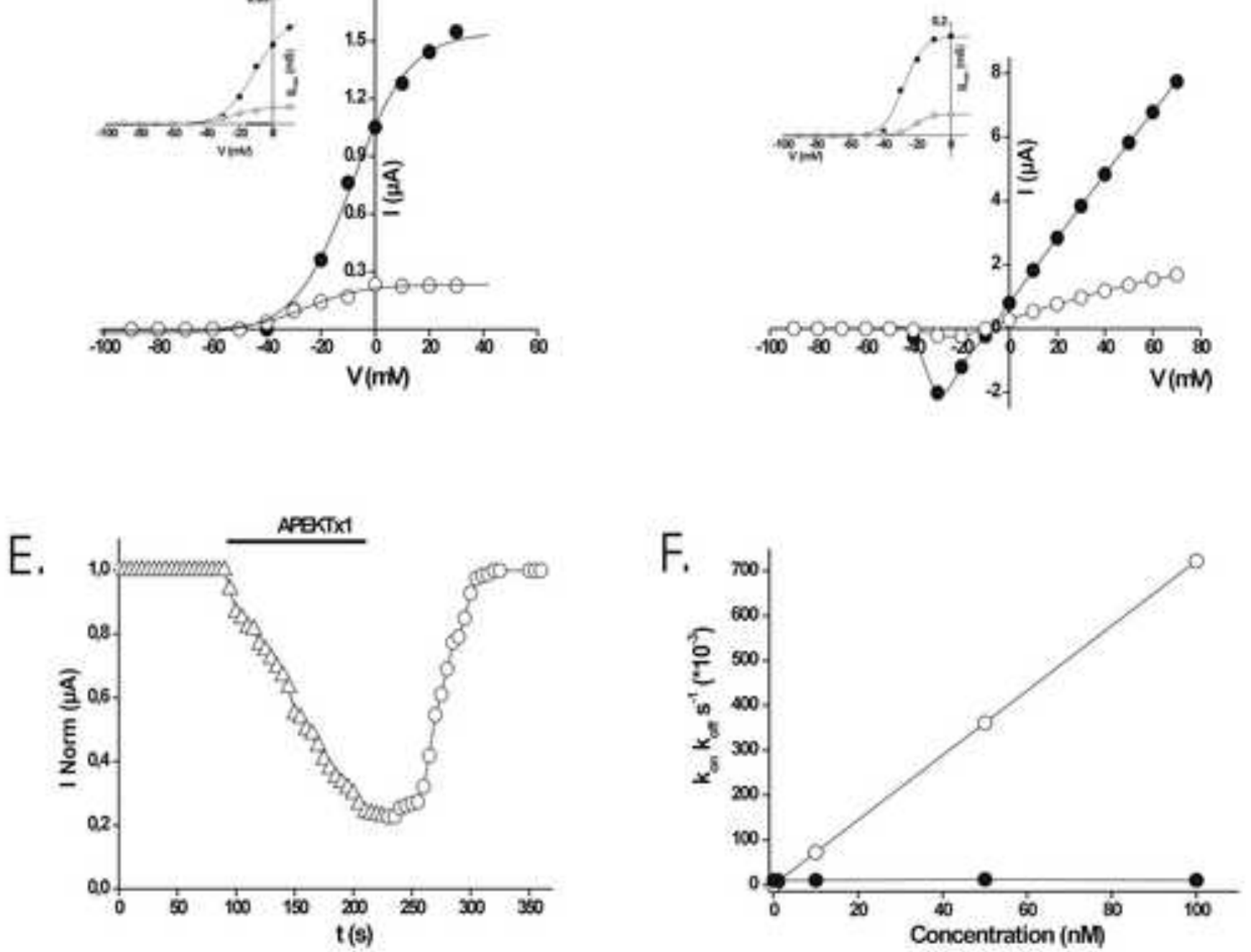
rKv1.1 FAEAEEAESHESSIPDAFWWAVVSMTTVGYGDMYPVTIGGK rKv1.1m FAEAEEPSSHESSIPDAFWWAVVSMTTVGYGDMHPVTIGGK זKV1.2 FAEADERESQEPSIPDAEWWAVVSMTTVGYGDMVPTTIGGK hKv1.3 EAEADDPTSGESSIPDAFWWAVVTMTTVGYGDMHPVTIGGK rKv1.4 FAEADEPTTHEQSIPDAFWWAVVTMTTVGYGDMKPITVGGK rKv1.5 FAEADNQGTHESSIPDAFWWAVVTMTTVGYGDMRPITVGGK mkv1.6 FAEADDDDSLEPSIPDAFWWAVVTMTTVGYGDMYPMTVGGK
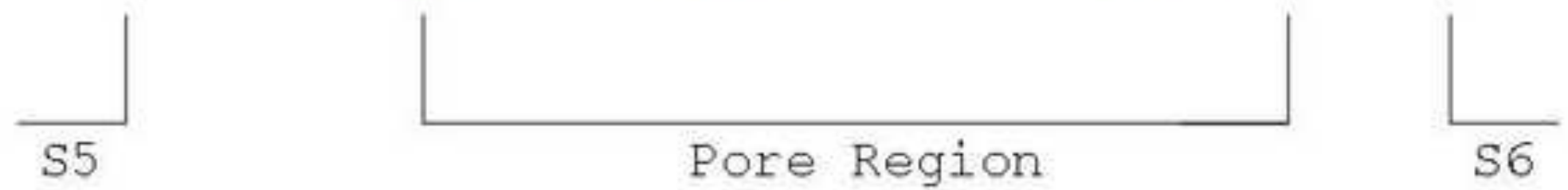


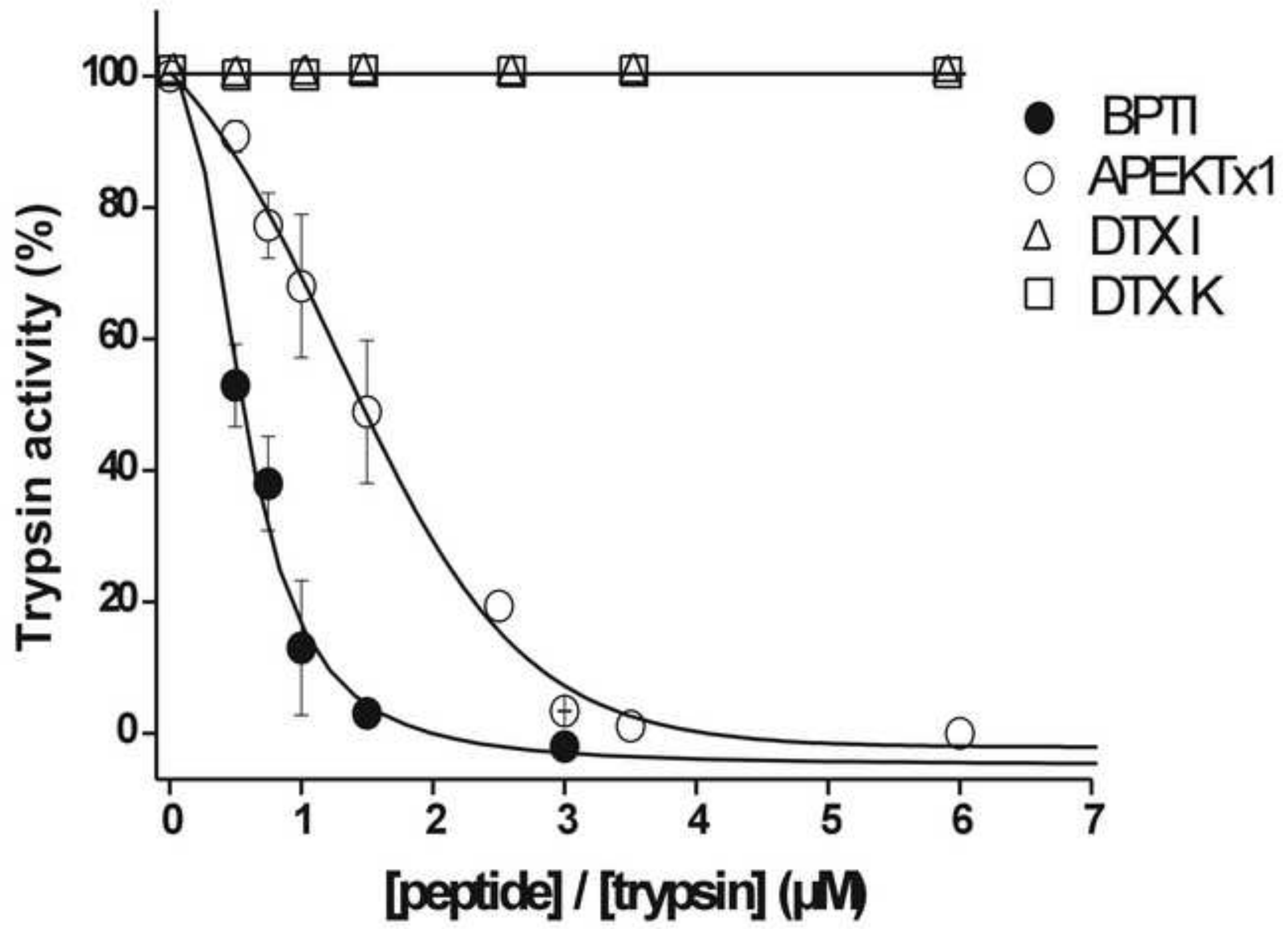

rage $2 U$ or $2 \angle$ 

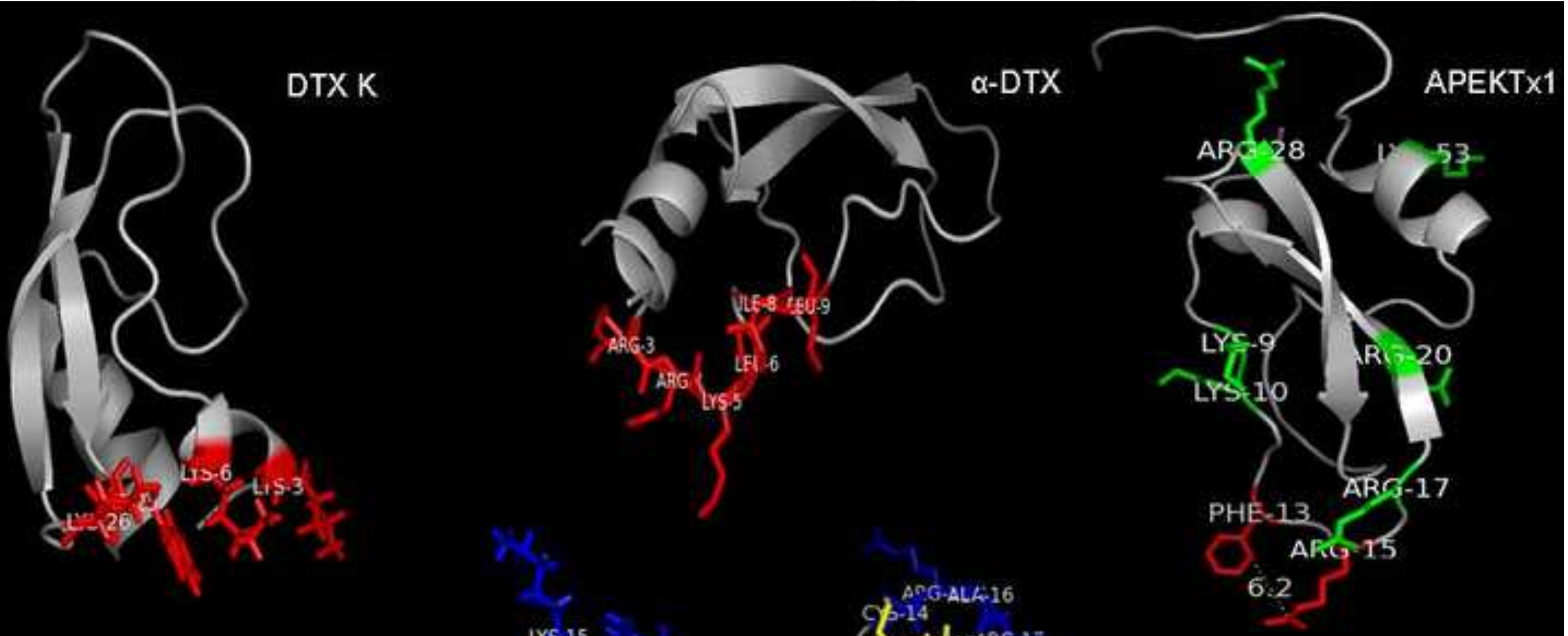

BPTI
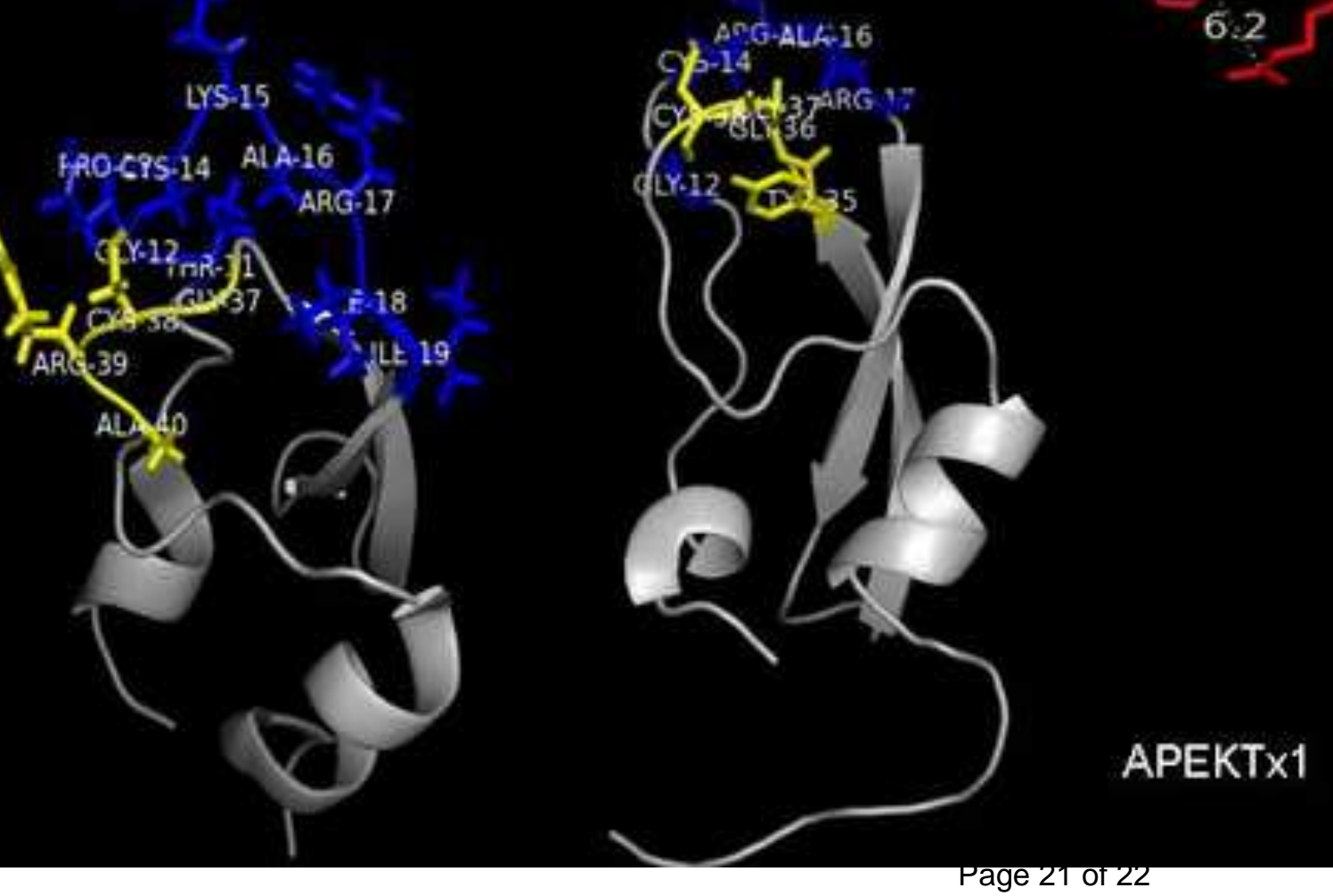
APEKTx 1 is a potent and selective $K_{V}$ blocker and protease inhibitor
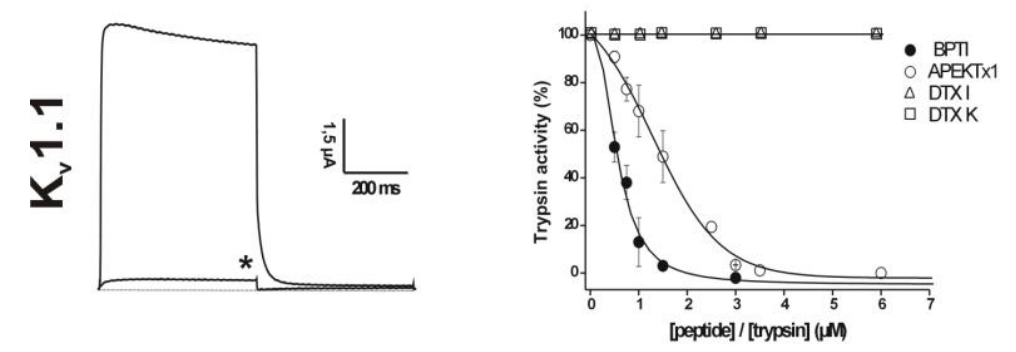